\title{
Intraseasonal Tropical Cyclogenesis Prediction in a Global Coupled Model System
}

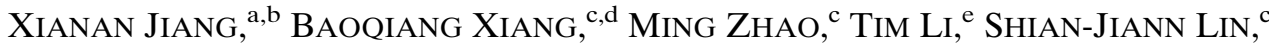 \\ ZHUO WANG, ${ }^{\mathrm{f}}$ AND JAN-HUEY CHEN ${ }^{\mathrm{c}, \mathrm{d}}$ \\ ${ }^{\text {a } J o i n t ~ I n s t i t u t e ~ f o r ~ R e g i o n a l ~ E a r t h ~ S y s t e m ~ S c i e n c e ~ a n d ~ E n g i n e e r i n g, ~ U n i v e r s i t y ~ o f ~ C a l i f o r n i a, ~ L o s ~ A n g e l e s, ~}$ \\ Los Angeles, California \\ ${ }^{\mathrm{b}}$ Jet Propulsion Laboratory, California Institute of Technology, Pasadena, California \\ ${ }^{\mathrm{c}}$ NOAA/Geophysical Fluid Dynamics Laboratory, Princeton University, Princeton, New Jersey \\ ${ }^{\mathrm{d}}$ University Corporation for Atmospheric Research, Boulder, Colorado \\ ${ }^{\mathrm{e}}$ Department of Atmospheric Sciences, University of Hawai'i at Mānoa, Honolulu, Hawaii \\ ${ }^{\mathrm{f}}$ University of Illinois at Urbana-Champaign, Urbana, Illinois
}

(Manuscript received 7 July 2017, in final form 10 April 2018)

\begin{abstract}
Motivated by increasing demand in the community for intraseasonal predictions of weather extremes, predictive skill of tropical cyclogenesis is investigated in this study based on a global coupled model system. Limited intraseasonal cyclogenesis prediction skill with a high false alarm rate is found when averaged over about 600 tropical cyclones (TCs) over global oceans from 2003 to 2013, particularly over the North Atlantic (NA). Relatively skillful genesis predictions with more than 1-week lead time are only evident for about $10 \%$ of the total TCs. Further analyses suggest that TCs with relatively higher genesis skill are closely associated with the MaddenJulian oscillation (MJO) and tropical synoptic waves, with their geneses strongly phase-locked to the convectively active region of the MJO and low-level cyclonic vorticity associated with synoptic-scale waves. Moreover, higher cyclogenesis prediction skill is found for TCs that formed during the enhanced periods of strong MJO episodes than those during weak or suppressed MJO periods. All these results confirm the critical role of the MJO and tropical synoptic waves for intraseasonal prediction of TC activity. Tropical cyclogenesis prediction skill in this coupled model is found to be closely associated with model predictability of several large-scale dynamical and thermodynamical fields. Particularly over the NA, higher predictability of low-level relative vorticity, midlevel humidity, and vertical zonal wind shear is evident along a tropical belt from the West Africa coast to the Caribbean Sea, in accord with more predictable cyclogenesis over this region. Over the extratropical NA, large-scale variables exhibit less predictability due to influences of extratropical systems, leading to poor cyclogenesis predictive skill.
\end{abstract}

\section{Introduction}

As one of the most disastrous extreme weather systems, tropical cyclones (TCs) pose great threats to human life and property. Improving prediction of TC activity, therefore, has profound socioeconomic impacts. While short-range forecasts (up to one week) and seasonal outlooks of TC activity have been routinely issued by operational forecast centers and institutes, predictions of TCs on intraseasonal time scales (from one week to several weeks) have not been well developed, largely due to underexploited predictability sources for TC prediction on this intermediate time scale. For short-range TC forecasts, the skill is essentially from the initial conditions, and

Corresponding author: Dr. Xianan Jiang, xianan@ucla.edu forecasts are usually realized by integrating high-resolution, in many cases limited-area, dynamical models with sophisticated data assimilation systems that focus great effort on deriving an accurate characterization of the initial condition and its uncertainty. On the other hand, predictability of seasonal TC forecasts largely relies on slowly varying large-scale elements, such as the sea surface temperature (SST; e.g., Gray 1984; Goldenberg and Shapiro 1996). For TC prediction on the intraseasonal time scale, the Madden-Julian oscillation (MJO; Madden and Julian 1994) is generally considered one of the primary predictability sources, ${ }^{1}$ based on widely reported modulations of

\footnotetext{
${ }^{1}$ In this study, the term MJO is used to represent not only the equatorially trapped eastward propagating intraseasonal variability (ISV) mode, but also the meridionally migrating monsoonal ISV during boreal summer.
} 
TC activity by the MJO over global oceans (e.g., Liebmann et al. 1994; Maloney and Hartmann 2000a; Dickinson and Molinari 2002; Bessafi and Wheeler 2006; Fu et al. 2007; Klotzbach 2010; Ventrice et al. 2011; Li and Zhou 2013; Ventrice et al. 2012; Jiang et al. 2012b; Zhao et al. 2015). Additionally, SST and convectively coupled equatorial waves (CCEWs) could also provide partial predictability for TC activity (e.g., Frank and Roundy 2006; Dunkerton et al. 2009; Vitart 2010; Chen and Chou 2014).

While significant progress over the past decades has been made in understanding the fundamental physics of the MJO (e.g., Zhang 2005; Lau and Waliser 2012), achieving credible MJO simulations in general circulation models (GCMs) has been challenging even in their latest generations (e.g., Jiang et al. 2012b, 2013; Hung et al. 2013; Jiang et al. 2015; Neena et al. 2017; Jiang 2017; Ahn et al. 2017). Until the last decade, useful predictive skill of the MJO had generally been limited to only $1-2$ weeks (Hendon et al. 2000; Vitart et al. 2007; Lin et al. 2008; Agudelo et al. 2009), with statistical models often outperforming dynamical models (e.g., Jones et al. 2004; Seo et al. 2005; Waliser 2006; Jiang et al. 2008). As a result, limited previous efforts in exploring prediction skill of intraseasonal TC activity were mainly based on statistical approaches (e.g., Frank and Roundy 2006; Leroy and Wheeler 2008; Vitart et al. 2010; Slade and Maloney 2013).

In recent years, the improvements in model physics, spatial resolution, and data assimilation systems have led to significant increases in the predictive skill of the MJO to 2-4 weeks (Bechtold et al. 2008; Vitart and Molteni 2010; Rashid et al. 2011; Waliser 2012; Wang et al. 2014; Neena et al. 2014b; Lee et al. 2015; Xiang et al. 2015a). Meanwhile, the capability of adopting global high-resolution grids in several models-including the European Center for Medium-Range Weather Forecasts (ECMWF) Integrated Forecast System (ECIFS) and the NOAA Geophysical Fluid Dynamics Laboratory (GFDL) High Resolution Atmospheric Model (HiRAM) - makes it possible to explicitly resolve TC formation in these models (e.g., Van der Grijn et al. 2004; Zhao et al. 2009). Particularly, these "TC permitting" global models are able to represent modulation of TC activity by the $\mathrm{MJO}$ as in the observations (e.g., Vitart 2009; Jiang et al. 2012b).

Inspired by these encouraging modeling achievements, recently there has been increasing enthusiasm in the community in exploring dynamical intraseasonal TC predictability (e.g., Vitart et al. 2010; Elsberry et al. 2010; Belanger et al. 2010; Gall et al. 2011; Belanger et al. 2012; Elsberry et al. 2014; Xiang et al. 2015b; Lee et al. 2018; Wang et al. 2018), with many of them based on the EC-IFS hindcasts. It has been shown that predictions from the EC-IFS can provide useful guidance on intraseasonal prediction of TC genesis and movement, particularly over the western Pacific (e.g., Elsberry et al. 2010; Belanger et al. 2010; Tsai et al. 2013). By analyzing predictions over the Atlantic Ocean from EC-IFS during 2008 and 2009, it was shown that the predictability of TC activity is sensitive to the phase and intensity of the MJO at the forecast initial time (Belanger et al. 2010), suggesting an important role of the MJO for intraseasonal TC predictions. Additionally, Vitart et al. (2010) illustrated more skillful dynamical predictions by EC-IFS for the first two weeks of prediction of weekly TC activity over the southern Indian Ocean than a statistical model by Leroy and Wheeler (2008).

By analyzing the NOAA Global Ensemble Forecasting System (GEFS) reforecasts, a recent study by Wang et al. (2018) investigated the predictability of cyclogenesis over the North Atlantic (NA) under different synoptic flow regimes or tropical cyclogenesis pathways. By employing two metrics characterizing the low-level baroclinicity and upper-level forcing of the environmental state for TC development, five tropical cyclogenesis pathways were categorized by McTaggart-Cowan et al. (2013), including nonbaroclinic (NBC), low-level baroclinic (LBC), troughinduced, weak, and strong tropical-transition pathways [see McTaggart-Cowan et al. (2013) and Wang et al. (2018) for details]. It was suggested that TC genesis associated with purely tropical pathways (e.g., NBC and LBC) is more predictable, whereas lower predictability of cyclogenesis is found over the extratropical NA, where the tropical-transition pathways prevail due to influences by extratropical processes (Wang et al. 2018), in accord with previous findings from several other studies (e.g., Elsberry et al. 2014; Komaromi and Majumdar 2014; Davis et al. 2016).

Based on a recently updated version of the GFDL coupled climate model system at a $50-\mathrm{km}$ horizontal resolution, predictability of TC genesis was explored in Xiang et al. (2015b) with a case study on two destructive landfalling TCs, Atlantic Hurricane Sandy (2012) and the western Pacific Supertyphoon Haiyan (2013). It was found that geneses of these two TCs are highly predictable with a lead time of about 11 days, which benefited from the model's skillful prediction of the MJO and tropical easterly waves (Xiang et al. 2015a,b).

Because the study of Xiang et al. (2015b) only focused on two tropical cyclogenesis events, questions remain: How predictable is tropical cyclogenesis in general beyond the weather time scale? What are the main factors associated with the intraseasonal predictability of tropical cyclogenesis? In this study, we extend the analyses of Xiang et al. (2015b) by examining tropical cyclogenesis prediction for more than 600 TCs during 11 years from 
2003 to 2013 based on the new GFDL coupled forecast system. A specific focus is to explore the common characteristics of TCs that are more predictable in their geneses on the intraseasonal time scale. Note that because of the relatively coarse resolution $(50 \mathrm{~km})$, the lack of a sophisticated assimilation system to generate the initial conditions, and a simple ensemble scheme used in this forecast system, it is not our intention to emphasize the model prediction skill of tropical cyclogenesis in the first several days of forecasts and to compare this coupled prediction system to current operational weather forecasting systems. The structure of this manuscript is as follows. The recently developed GFDL coupled model, hindcast schemes, and observational datasets are described in section 2. In section 3, predictive skill of tropical cyclogenesis during the 11 years is assessed and possible factors responsible for relatively higher cyclogenesis prediction skill are discussed. A summary of the main findings from this study and a brief discussion are presented in section 4 .

\section{Methods}

\section{a. The new GFDL coupled model system and hindcast schemes}

In this study, hindcasts are conducted by using a recently updated version of the GFDL coupled model, the same as the one used in Xiang et al. (2015a,b). This model is based on the Forecast-Oriented Low Ocean Resolution (FLOR) version of the GFDL model (Vecchi et al. 2014) but with a new convection scheme that is referred to as a double-plume convection (DPC) scheme (Zhao et al. 2018). The DPC scheme is mainly modified based on the University of Washington shallow cumulus scheme (Bretherton et al. 2004) used in GFDL HiRAM (Zhao et al. 2009), with a major update by introducing an additional bulk plume to represent both deep and shallow convection. The atmospheric model has a roughly $50-\mathrm{km}$ horizontal grid spacing and 32 vertical levels using a cubed-sphere finite-volume dynamic core (Putman and Lin 2007). The horizontal resolution for the ocean model is about $1^{\circ}$ with 50 vertical levels (10-m resolution in the upper $100 \mathrm{~m})$.

The initial conditions for atmosphere and ocean were obtained through a nudging approach toward observations following Zhang et al. (2014), and used by Xiang et al. (2015a,b). The atmospheric nudging fields include winds, temperature, geopotential height, and surface pressure from National Centers for Environmental Prediction (NCEP) Global Forecast System analysis data. The model SST is nudged to daily high-resolution NOAA Optimum Interpolation SST Analysis (OISST v2; Reynolds et al. 2007). Before nudging, the coupled system was first spun up for 300 years to allow the ocean (particularly the upper ocean) to fully adjust. Nudging is then conducted starting from January 2002 with time intervals of 6-hourly for atmospheric variables and daily for SST, and hourly outputs were archived to create the initial conditions for hindcast experiments. Hindcasts were conducted every 5 days (the 1st, 6th, 11th, 16th, $21 \mathrm{st}$, and 26th of the month) for each month from June to October during the 11 years from 2003 to 2013. For hindcasts initialized on each day, a series of 50-day free integrations with initial conditions from successively two hours apart (i.e., at 0000, 0200, 0400, .., 2000, and 2200 UTC) constitute 12 ensemble members for the hindcast on that particular day. A total of 3960 hindcasts (11 years $\times$ 5 months $\times 6$ days $\times 12$ members) were produced during the 11 summer seasons.

Note that we fully realize the limitation of this prediction system by employing a nudging approach in generating initial conditions rather than using a sophisticated assimilation system and also a simple scheme in constructing ensemble members by slightly shifting the initialization time instead of a perturbation scheme accounting for uncertainties in initial conditions and model physics (e.g., Molteni et al. 1996; Toth and Kalnay 1997). Considering the outstanding MJO predictive skill by this coupled prediction system (Xiang et al. 2015a), one of the main focuses of this study is to investigate how predictability of intraseasonal TC genesis can be achieved given model's capability in depicting large-scale forcing associated with the MJO.

To detect TCs in model hindcasts, a tracking method is adopted by using the 6-hourly instantaneous sea level pressure (SLP), 850-hPa vorticity, and upper-tropospheric (300-500 hPa) temperature following Harris et al. (2016). First, cyclone centers are identified by minima in SLP fields of depression at least of $2 \mathrm{hPa}$ compared with their surroundings. Further criteria of a warm core structure with $300-500-\mathrm{hPa}$ temperature at least $2^{\circ} \mathrm{C}$ warmer from the surrounding local mean and a maximum $850-\mathrm{hPa}$ cyclonic vorticity of at least $1.5 \times 10^{-4} \mathrm{~s}^{-1}$ (negative in Southern Hemisphere) over cyclone centers are applied to filter out weak or disorganized systems. The location of the TC center is then fine-tuned by fitting a biquadratic to the SLP field and placing the center at its minimum. The identified TCs also need to meet the criterion of a minimum lifetime of $72 \mathrm{~h}$. Details of the cyclone tracking approach can be found in Harris et al. (2016). Sensitivity tests show that results based on this approach are largely similar to those by using other tracking schemes (e.g., Zhao et al. 2009).

\section{b. Observational dataset}

The observational TC data are from the International Best Track Archive for Climate Stewardship (IBTrACS, 


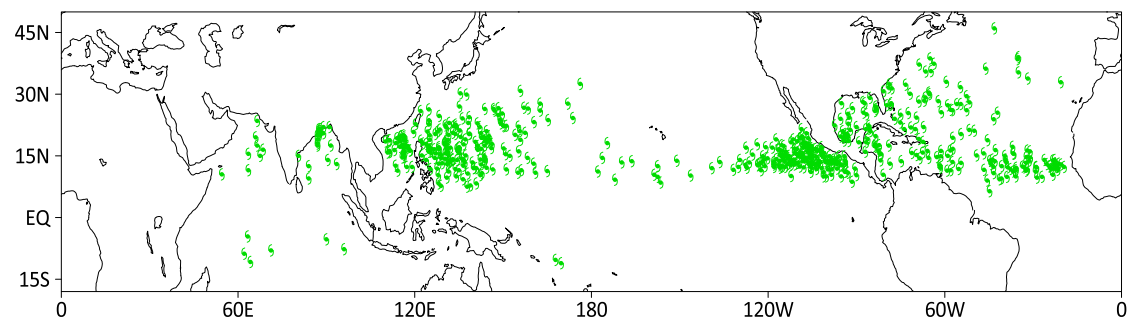

FIG. 1. Genesis locations of global tropical cyclones during boreal summer (June-November) from 2003 to 2013.

version v03r06; Knapp et al. 2010), which provides observations of 6-hourly TC location and maximum wind speed. To identify large-scale signals associated with the local MJO and tropical synoptic waves in each ocean basin, daily TRMM-based rainfall observations (version 3B42 v7; Huffman et al. 2007) and 850-hPa vorticity from the ECMWF ERA-Interim reanalysis (Dee et al. 2011) for the same period of 2003-13 are analyzed. Additionally, a global MJO index [i.e., the real-time multivariate MJO (RMM) index following Wheeler and Hendon (2004)] is also used to examine general relationship between the MJO and TC genesis over global oceans in both observations and model hindcasts.

\section{Results}

In this study, cyclogenesis is defined at the time when the cyclone reaches tropical storm status [with wind speed $\geq 17.5 \mathrm{~m} \mathrm{~s}^{-1}$ in observations and $\geq 15.2 \mathrm{~m} \mathrm{~s}^{-1}$ in model hindcasts following Zhao et al. (2009) and Xiang et al. (2015b)]. Note that the wind speed threshold for model tropical storms was adjusted based on the model resolution (Walsh et al. 2007), which leads to more comparable global tropical storm counts to the observed (Zhao et al. 2009; Xiang et al. 2015b). Figure 1 shows genesis locations of the observed $657 \mathrm{TCs}^{2}$ during the 11 summers from 2003 to 2013 over global oceans, which are largely clustered over the western Pacific (WP) and eastern Pacific (EP), with more spread over the North Atlantic and also a few genesis events over the Indian Ocean.

\section{a. Climatology of tropical cyclogenesis in model hindcasts}

First we examine how the observed climatological distribution of TC genesis probability is represented in model hindcasts. For this purpose, following the

\footnotetext{
${ }^{2}$ Hereafter, the term TC is used to specifically represent tropical cyclone with minimum intensity at the tropical storm category.
}

approach by Belanger et al. (2010), daily gridded global TC genesis probability patterns are first constructed on $1^{\circ} \times 1^{\circ}$ grids for both observations and model hindcasts. For hindcasts, daily genesis probability is determined by the percentage of the number of ensemble members out of the total 12 members that detect TC formation within $2.5^{\circ}$ of each grid point on that particular day. For observations, gridded daily genesis probability on a particular grid is specified as 1 or 0 if TC genesis was observed or not observed within $2.5^{\circ}$ of that grid. Then global gridded climatological genesis probability in hindcasts (Fig. 2b) can be derived by averaging daily patterns from hindcasts up to two weeks (14 days) initialized on each day during the 11 years. For a fair comparison, the observed climatological genesis probability pattern (Fig. 2a) is also calculated by averaging daily patterns over the same days as for the hindcasts.

Consistent with TC genesis locations for the 11-yr period shown in Fig. 1, the core TC genesis regions are observed over off-equatorial warm SST regions in both the WP and EP (Fig. 2a). Over the NA, while active TC genesis is largely observed over the main development region (MDR) off the West Africa coast, the Caribbean Sea, and the Gulf of Mexico, a widespread TC genesis is evident over the broad NA basin, including the subtropical western NA. The observed climatological TC genesis probability is generally well captured in hindcasts (Fig. 2b), although the model slightly underestimates genesis probability over the WP, EP, and subtropical NA, while it overestimates the probability over the north Indian Ocean. Over the eastern NA, hindcasts largely capture cyclogenesis near the Cape Verde islands, whereas they underestimate TC formation farther downstream. A similar model bias in tropical cyclogenesis over the tropical eastern NA is also evident in predictions based on the NCEP GEFS ( $\mathrm{Li}$ et al. 2016). Because of the relatively small numbers of cyclogenesis over the Indian Ocean as well as very different seasonal variations of TC activity in this area, in the following we mainly confine our analyses to TC genesis over the WP, EP, and NA. 

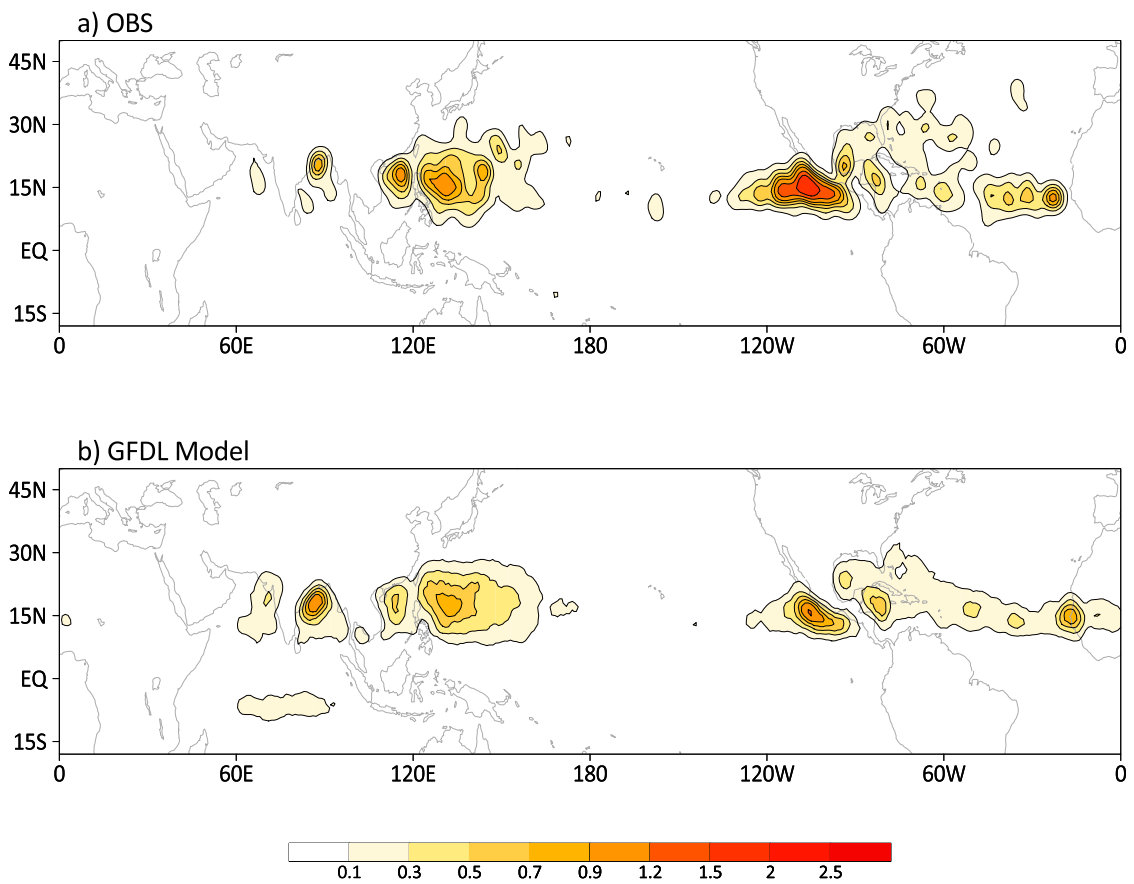

FIG. 2. Climatological cyclogenesis probability distribution based on (a) observations and (b) hindcasts from the coupled GFDL model system with leads from 1 to 14 days. Units are TC genesis counts during a boreal summer season (June-November).

\section{b. Tropical cyclogenesis predictive skill}

Next, the predictive skill of cyclogenesis for the 594 TCs over the WP, EP, and NA during the 11 summers is assessed following the same approach used by Xiang et al. (2015b). For each observed TC genesis, a successful cyclogenesis prediction is counted if the predicted genesis occurs within 2 days of the observed genesis time and $8^{\circ}$ of the observed location. ${ }^{3}$ Prediction skill of the observed TC genesis at a certain forecast lead time is then defined as the percentage of the number of ensemble members out of the total 12 that make the correct forecasts. Averaged genesis prediction skill as a function of forecast lead days for all the 594 TCs as well as for TCs at each ocean basin is shown by bar graphs in Fig. 3. Since hindcasts are initialized using a simple nudging approach rather than a sophisticated assimilation system as in the operational forecast systems, an adjustment of initial conditions to model physics is unavoidable. As a result, the predictive skill is relatively

\footnotetext{
${ }^{3}$ Note that TC genesis prediction skill can be affected by this threshold. While it is largely comparable to those used in other studies (e.g., Halperin et al. 2013, 2016; Wang et al. 2018), this threshold follows that by Xiang et al. (2015b) in quantifying genesis prediction skill for Hurricane Sandy and Supertyphoon Haiyan, so that general TC genesis prediction skill presented in this study can be compared to that for Sandy and Haiyan previously reported.
}

low in the first one or two days of forecasts, and the average cyclogenesis skill over the three basins peaks on day 3 with skill of about 30\% (Fig. 3a). This predictive skill is much lower than that of Sandy and Haiyan as reported by Xiang et al. (2015b), both of which exhibit genesis skill of $50 \%$ up to the 11-day forecast lead. Comparison of predictive skill over different ocean basins (Figs. 3b-d) suggests that cyclogenesis prediction over the WP and EP is slightly more skillful than that over the NA, in agreement with lower predictability of TC activity over the NA than in the WP as previously reported based on EC-IFS ensemble forecasts (Elsberry et al. 2014). Also worth noting is that relatively higher TC genesis skill is found during October than other months (figure not shown); the reason for this remains unclear.

The false alarm rate (FAR) of predicted geneses as a function of forecast lead is further examined. For each individual ensemble member forecast, if cyclogenesis is identified on a particular day, but there is no TC genesis observed within 2 days and $8^{\circ}$ of the forecasted TC genesis time and location, this forecast is counted as a false alarm and flagged with a value of 1 . Note that false alarm calculations on forecast lead days 1 and 2 are adjusted as a result of many well-developed TCs present on forecast initialization days in the observations but captured as new geneses in model hindcasts. Therefore, 
a) Global (EP,WP,NA)

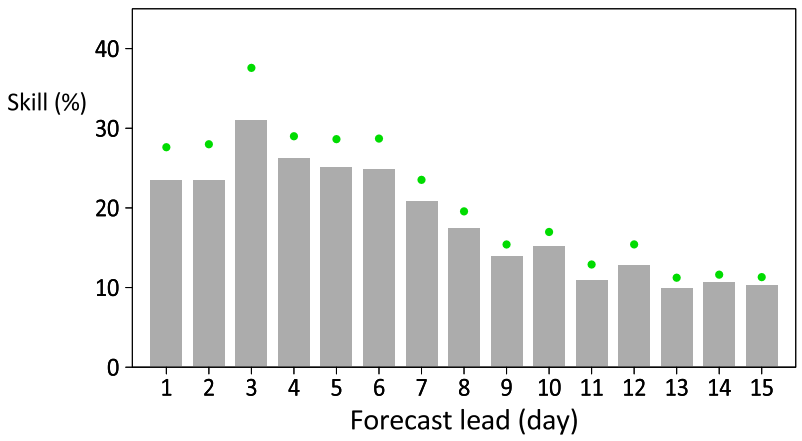

c) EP

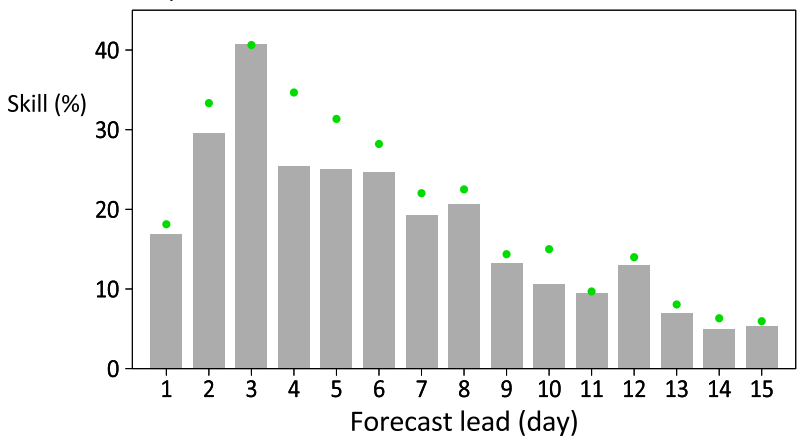

b) WP

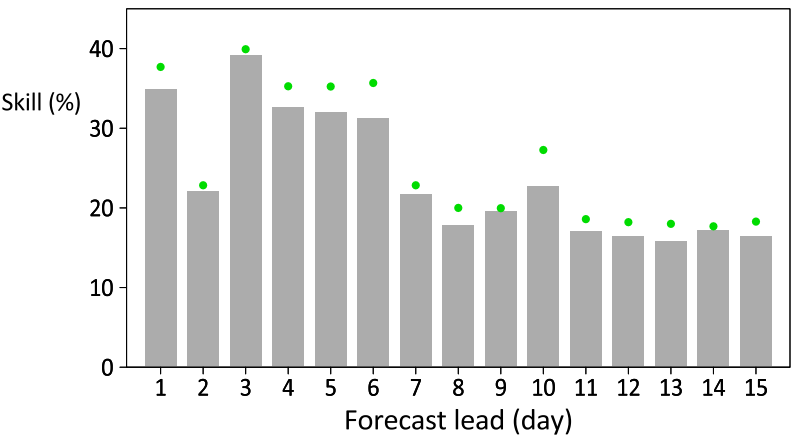

d) NA

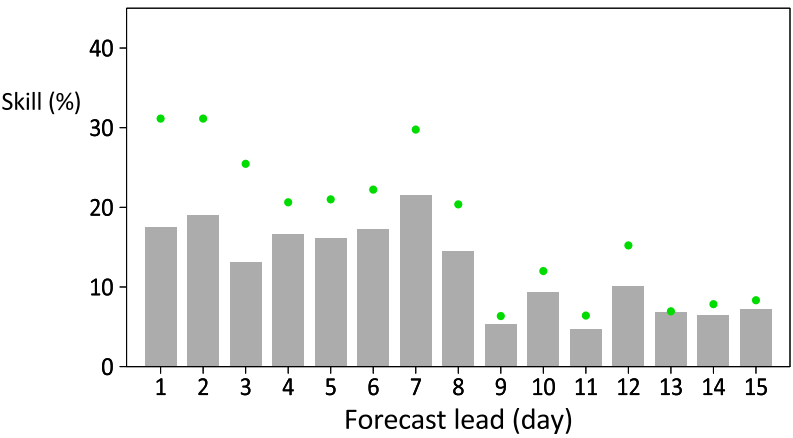

FIG. 3. Bar graphs indicate cyclogenesis predictive skill as a function of forecast lead days for TCs over (a) the EP, WP, and NA combined and the (b) WP, (c) EP, and (d) NA separately. The green dots are similar to the bar graphs, but for genesis skill for TCs formed over tropical regions of the three ocean basins, defined as tropical WP $\left(110^{\circ}-170^{\circ} \mathrm{E}, 5^{\circ}-25^{\circ} \mathrm{N}\right)$, tropical EP $\left(130^{\circ}-80^{\circ} \mathrm{W}, 5^{\circ}-18^{\circ} \mathrm{N}\right)$, and tropical NA $\left(80^{\circ}-20^{\circ} \mathrm{W}, 5^{\circ}-18^{\circ} \mathrm{N}\right)$.

these predictions are excluded from the false alarm cases when the model predicts TC genesis on forecast days 1 and 2 , and a TC is observed within $8^{\circ}$ and 2 days of the predicted TC genesis, regardless of whether the observed TC is a new genesis or already developed.

The FAR as a function of forecast lead can then be derived by the sum of false alarm flags normalized by the total numbers of individual forecasts (Fig. 4). Since the validation is conducted based on each individual member forecast, Fig. 4 illustrates that the FARs quickly increase with forecast leads in all three ocean basins. For example, over the WP (blue) and EP (red), a FAR of about $20 \%$ is found in 2-day forecasts, and then it quickly increases to about $60 \%-70 \%$ on day 7 . It is also suggested by Fig. 4 that there are relatively smaller FARs for cyclogenesis in the WP and EP than in the NA in general. The FAR for predictions over the NA quickly reaches about $60 \%-70 \%$ on day 4 and steadily increases with forecast leads. This result further indicates relatively lower predictability of cyclogenesis over the NA. It is worth noting that a high FAR of about $70 \%-80 \%$ within 1 -week lead time for TC genesis predictions over the NA is also found in the NCEP GEFS (Wang et al. 2018).
Since genesis predictive skill averaged over the global TCs as suggested by Fig. 3 is much lower than that for Sandy and Haiyan as reported in Xiang et al. (2015b), this then brings up a question of whether there are common features for TCs for which genesis is more predictable based on this coupled forecast system. In light of the predictive skill of Sandy and Haiyan as previously reported (e.g., about $50 \%$ at forecast lead day 11 ),

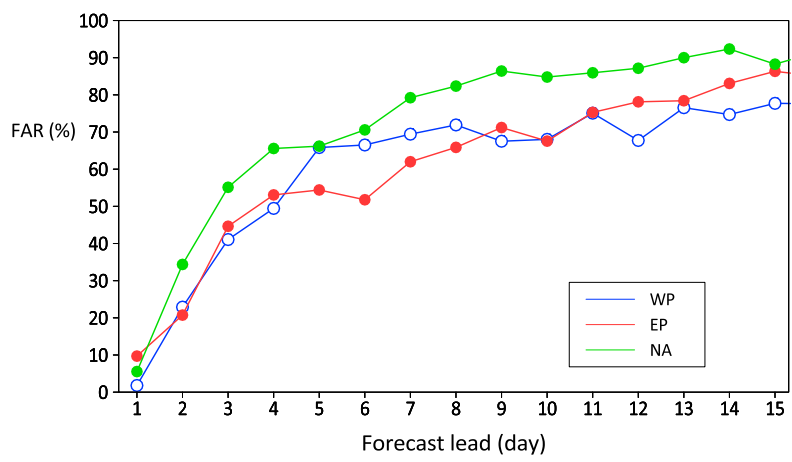

FIG. 4. FARs of tropical cyclogenesis predictions over the WP, $E P$, and NA. Please refer to the text for details of the definition of FAR. 
a) TCs with skillful genesis prediction

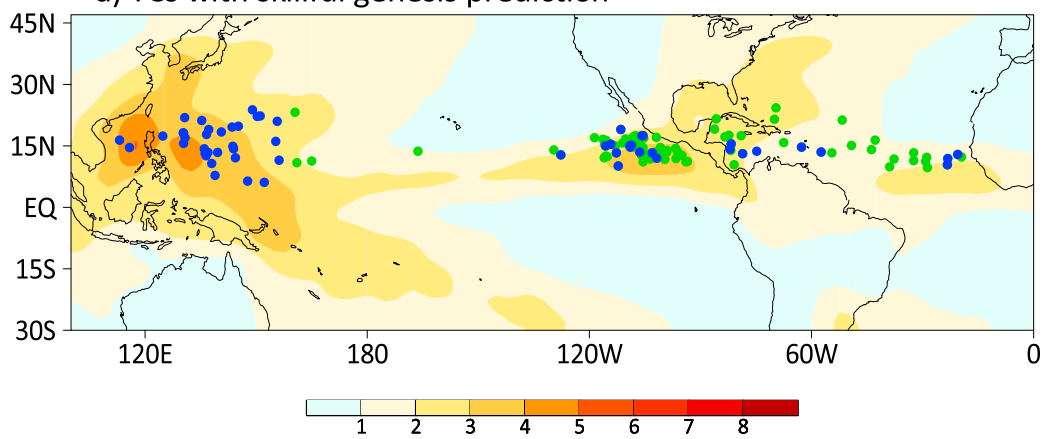

b) Prediction skill of genesis for selected skillful TCs

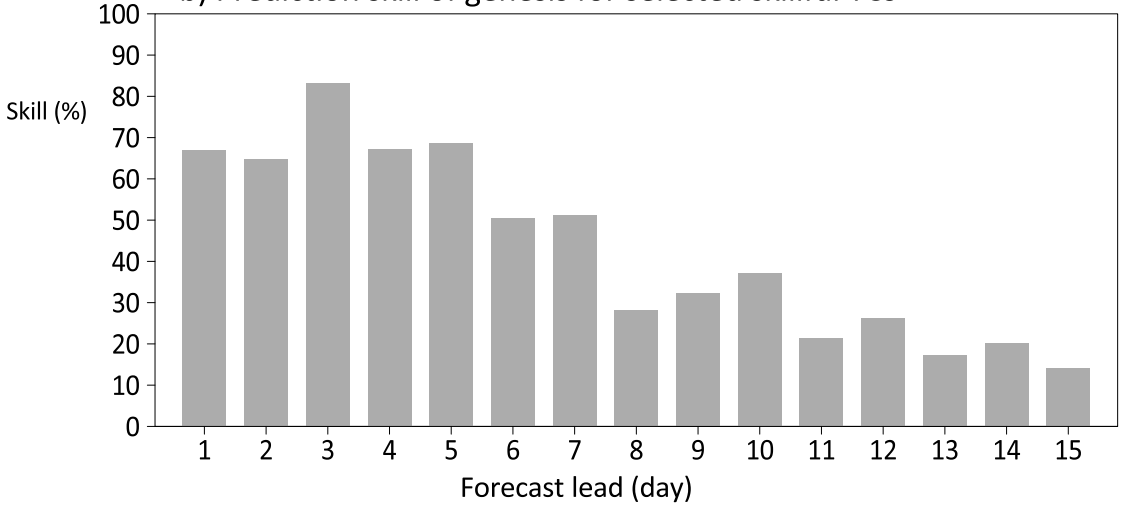

FIG. 5. (a) Genesis locations of TCs that exhibit higher predictive skill based on the GFDL coupled model system. TCs with a green color denote those where predictive skill is above $65 \%$ in forecasts during the first week, and those with a blue color denote TCs that show a predictive skill greater than $50 \%$ during the week- 2 forecasts. Shaded contours denote standard deviations of 20-70-day filtered daily summer rainfall anomalies $\left(\mathrm{mm} \mathrm{day}^{-1}\right)$. (b) Averaged cyclogenesis skill based on the selected more predictable TCs as shown in (a).

TCs with relatively higher genesis skill are then identified by applying a criterion that genesis predictive skill is above $65 \%$ in any prediction during the first week or above $50 \%$ during the second week. ${ }^{4}$ Figure 5 a illustrates genesis locations of TCs with relatively higher skill (174 out of total $597 \mathrm{TCs}$ ), with 119 of them identified by good skill in forecasts during week 1 (green dots), 30 TCs identified by good skill in both week 1 and week 2 , and the remaining 25 TCs identified by good skill of above $50 \%$ in week- 2 forecasts. The 55 TCs that exhibit high genesis skill in week-2 forecasts are denoted by blue dots in Fig. 5a. Over the WP and EP, it is clearly evident that TCs with higher genesis predictive skill are largely formed over the core warm SST regions to the north of the equator, collocated with the local monsoon trough over

\footnotetext{
${ }^{4}$ Total TC counts with relatively high genesis skill could be underestimated due to limited forecast sampling. There is a maximum of two predictions during each week for one particular observed TC since hindcasts were initialized every five days.
}

the WP and the intertropical convergence zone (ITCZ) over the EP. These regions are also characterized by vigorous activity of the MJO as indicated by the shaded contours in Fig. 5a, which denotes standard deviations of 20-70-day filtered daily summer rainfall anomalies, and tropical synoptic waves (not shown, but with largely similar distribution as the MJO activity over the WP and EP).

In the NA, the more predictable TC geneses spread over an elongated belt from the West African coast to the Caribbean Sea, generally collocated with the pathway of the African easterly waves (EWs), indicating that dynamical forcing associated with the EWs may provide predictability of TC formation over the NA. Also noteworthy is that model hindcasts largely exhibit limited cyclogenesis skill over the Gulf of Mexico and to the north of the Bahamas (cf. Fig. 5a and Fig. 1), where TCs are more susceptible to influences by extratropical systems. Since TCs forming over the Gulf of Mexico and the north of Bahamas make up a significant portion of 
the total TCs over the NA, this explains that the average genesis prediction skill over the NA is much lower than that over the WP and EP as shown in Fig. 3. Lower cyclogenesis skill over the NA also could be related to model biases in predicting TC genesis over this region (Fig. 2b), for example, by overpredicting TC genesis near the Cape Verde islands while underpredicting genesis over the subtropical western NA, as also found in the NCEP GEFS (Li et al. 2016).

Figure $5 \mathrm{~b}$ further illustrates the genesis predictive skill averaged over the above selected 174 TCs, and shows maximum skill of $80 \%$ at day 3 and skill of $50 \%$ persisting to the end of the first week. Some skill, although limited, can still be evident during week 2 . Note that among these 179 TCs, 55 of them (blue dots in Fig. 5a) exhibit skill into week 2, including Sandy (2012) and Haiyan (2013) as previously reported in Xiang et al. (2015b). These results thus suggest that the about 11-day prediction skill for Sandy and Haiyan as reported in Xiang et al. (2015b) tend to be exceptionally higher than that for most TCs based on this prediction system.

\section{c. Impacts of the MJO and synoptic waves on TC genesis prediction skill}

The higher cyclogenesis prediction skill over the tropical oceans as shown in Fig. 5a indicates that largescale forcing associated with tropical waves, such as the MJO and CCEWs, could play a critical role for TC genesis. This is further confirmed by relatively higher genesis prediction skill in general over tropical oceans as illustrated by the green dots in Fig. 3, especially over the NA (see Fig. 3 caption for definition of tropical region for each ocean basin). This notion is in concert with the recent study by Wang et al. (2018), which also suggests more predictable TC genesis over the NA under purely tropical pathways based on NCEP GEFS hindcasts. In a case study of TC prediction over the NA during 2012 based on EC-IFS forecasts, Elsberry et al. (2014) also found that more predictable TCs are generally associated with the African EWs.

Motivated by the above results, we proceed to further explore how influences from the MJO and tropical synoptic waves may affect TC genesis predictive skill. While it has been suggested that different CCEWs can play roles in regulating cyclogenesis (e.g., Dickinson and Molinari 2002; Frank and Roundy 2006; Kiladis et al. 2009; Chen and Chou 2014), in the following analyses we mainly focus on modulation of cyclogenesis by tropical depression-type waves (TDWs; Lau and Lau 1990; Sobel and Bretherton 1999; Li et al. 2003; Li 2006, 2012; Zhao et al. 2016) over the WP and EWs (Lau and Lau 1990; Dunkerton et al. 2009; Wang et al. 2010) over the EP and NA.
First, to examine how the observed MJO modulations of TC genesis are represented in model hindcasts, Fig. 6 presents spatial patterns of global tropical cyclogenesis probability anomalies during different MJO phases in both observations and model hindcasts during the first two weeks. Here, definition of the eight MJO phases is based on the observed global WheelerHendon MJO RMM indices. Consistent with previous reports on skillful MJO prediction in this model (Xiang et al. 2015a), and also the capability in depicting MJO influences on TC genesis in climate simulations from an earlier version of this model (Jiang et al. 2012a), the observed influences of the MJO on global TC genesis (left panels, Fig. 6) are well represented in hindcasts (right panels, Fig. 6), particularly over the WP and EP. For example, the largely enhanced TC geneses over the WP during MJO phases 4-7, and over the EP during MJO phases 6-8 and 1, are relatively well captured in hindcasts, although some differences are also noted between the observations and hindcasts. For example, the north-south dipole pattern of genesis probability anomalies over the EP during MJO phases 6-7 is not well captured in hindcasts. Also, over the NA, rather weak modulation of cyclogenesis by the MJO is noted in the observations, while systematic MJO impacts on TC genesis tend to be evident in hindcasts. The difference between model and hindcasts could be partially associated with model deficiencies in capturing the MJO mode or due to the limitation of the global RMM MJO index itself in representing the regional boreal summer MJO modes over different ocean basins (e.g., Lee et al. 2013; Neena et al. 2014a). In the following, to achieve a more accurate depiction of the relationship between the boreal summer MJO and tropical cyclogenesis, the dominant intraseasonal variability (ISV) modes over different ocean basins are derived separately based on local rainfall data rather than using the global RMM MJO index. While these regional intraseasonal variability modes during boreal summer over various ocean basins could be independent from the equatorial eastward propagating MJO mode, we use the term "MJO" to represent the general tropical intraseasonal variability in the following discussion for convenience.

Following Jiang et al. (2012a, 2014), the leading MJO modes over the WP and EP are identified by the extended empirical orthogonal function (EEOF) analyses (Weare and Nasstrom 1982) of daily 10-70-day bandpass-filtered TRMM rainfall anomalies from 2003 to 2013 over the WP $\left(60^{\circ}-160^{\circ} \mathrm{E}, 15^{\circ} \mathrm{S}-25^{\circ} \mathrm{N}\right)$ and EP $\left(140^{\circ}-90^{\circ} \mathrm{W}, 0^{\circ}-30^{\circ} \mathrm{N}\right)$ with a time lag of 31 days. Principal components (PCs) associated with the two leading quadratic EEOF modes, representing the 

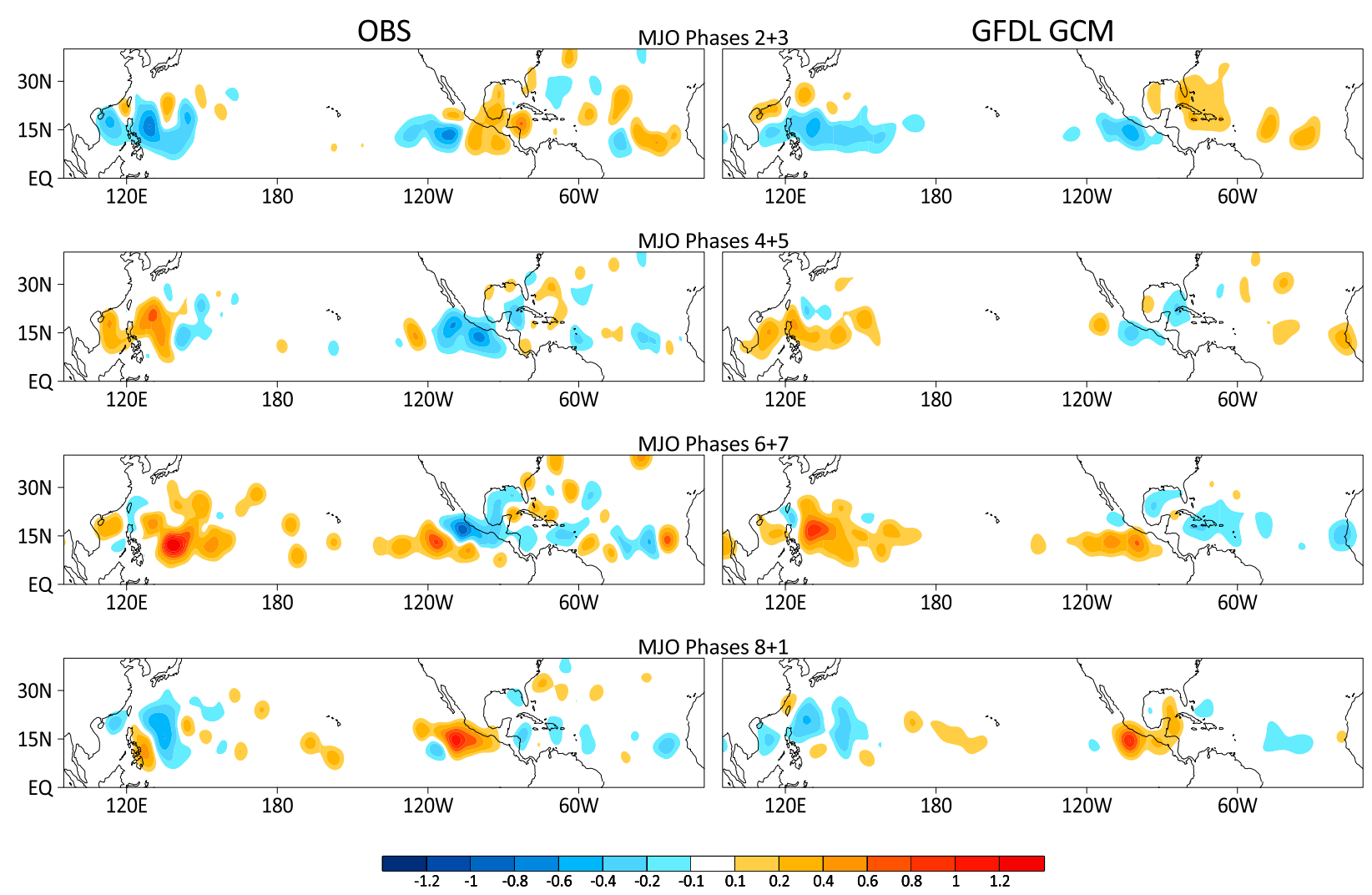

FIG. 6. Composite TC genesis probability anomalies as a function of MJO phases in (left) observations and (right) model hindcasts for the period of June-November 2003-13. The anomalies are computed relative to the 2003-13 climatology as shown in Fig. 2. MJO phases here are defined using the observed global Wheeler-Hendon MJO index. Units are TC genesis counts during a boreal summer season (June-November).

corresponding local MJO mode of each ocean basin, are then used to determine daily MJO amplitudes and phases (ranging from 1 to 8 ). Strong MJO days can be defined by daily two leading PCs with $\sqrt{\mathrm{PC}_{1}^{2}+\mathrm{PC}_{2}^{2}} \geq 1$. Composite anomalous rainfall patterns during each MJO phase can also be derived by averaging the 10-70-day filtered rainfall anomalies for each MJO phase. Since the leading ISV mode over the NA during the boreal summer is a quasi-biweekly (QBW) mode associated with the West Africa monsoon variability (e.g., Mounier and Janicot 2004; Mounier et al. 2008; Serra et al. 2014), a domain of $30^{\circ} \mathrm{W}-30^{\circ} \mathrm{E}, 10^{\circ} \mathrm{S}-30^{\circ} \mathrm{N}$ over the eastern NA is used for the EEOF analysis of rainfall anomalies to define phases of the leading ISV mode over the NA. Meanwhile, using an approach similar to that in Lau and Lau (1990) and Zhao et al. (2016), leading modes associated with the TDW or EW and their daily phases can be derived by EEOF of 2-8-day bandpass-filtered 850-hPa relative vorticity over the WP $\left(100^{\circ}-170^{\circ} \mathrm{E}, 5^{\circ} \mathrm{S}-30^{\circ} \mathrm{N}\right)$, EP $\left(140^{\circ}-80^{\circ} \mathrm{W}\right.$, $\left.0^{\circ}-30^{\circ} \mathrm{N}\right)$, and $\mathrm{NA}\left(90^{\circ} \mathrm{W}-20^{\circ} \mathrm{E}, 5^{\circ} \mathrm{S}-30^{\circ} \mathrm{N}\right)$ with a time lag of 11 days.
Figure 7a illustrates anomalous rainfall patterns during different phases of the boreal summer MJO mode over the Asian monsoon region, along with genesis locations of the previously identified more predictable TCs over the WP. The phase lock of these TC geneses to local MJO conditions is clearly evident. A majority of these more predictable TCs tend to form within the enhanced MJO convection or on its northern edge during phases $4+5$ and $6+7$. These TC geneses could be promoted by enhanced midlevel moisture over the MJO convective region and strengthening of monsoon trough associated with the slightly northward shifted low-level cyclonic vorticity relative to the convection (e.g., Jiang et al. 2004; Hsu et al. 2004; Camargo et al. 2009; Mao and Wu 2010; Huang et al. 2011; Li and Zhou 2013; Cao et al. 2014). The strong phase dependence of TC genesis on the MJO is further evident in Fig. 7e. About $91 \%$ of these more predictable TC geneses over the WP occurred during periods with strong MJO events, and $72 \%$ of them occurred during MJO phases from 4 to 6 .

The more predictable TC geneses over the WP during weak or suppressed MJO conditions indicated by Fig. 7d 
a) Phase $2+3$

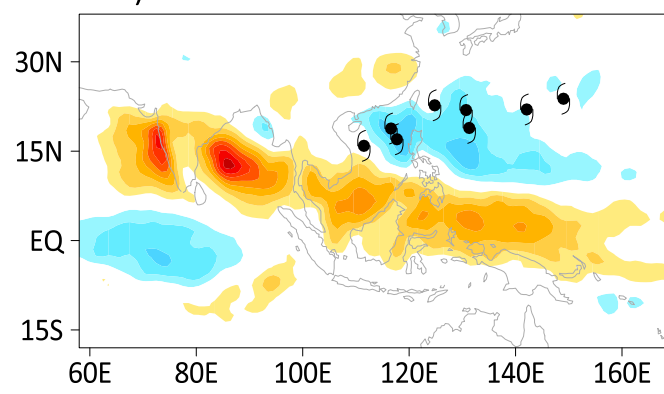

b) Phase $4+5$

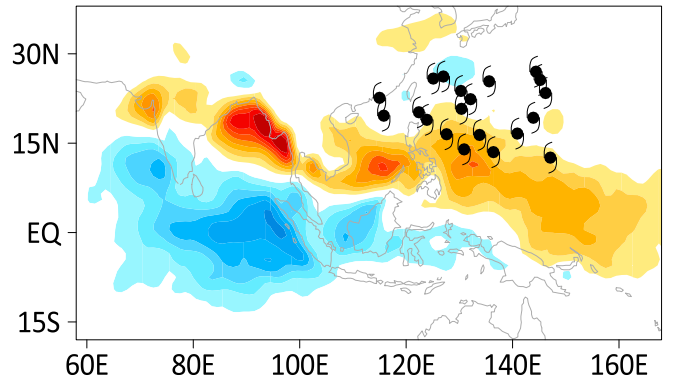

c) Phase 6+7

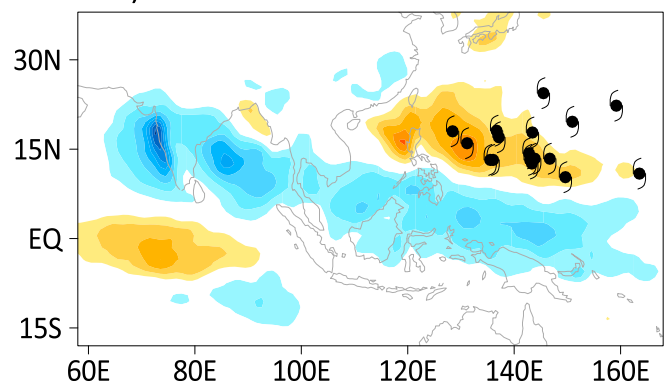

d) Phase $8+1$

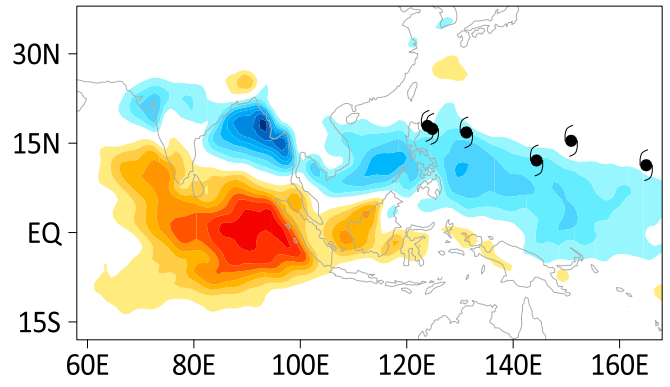

$\begin{array}{llllllllllllllll}-8 & -7 & -6 & -5 & -4 & -3 & -2 & -1 & 1 & 2 & 3 & 4 & 5 & 6 & 7 & 8\end{array}$

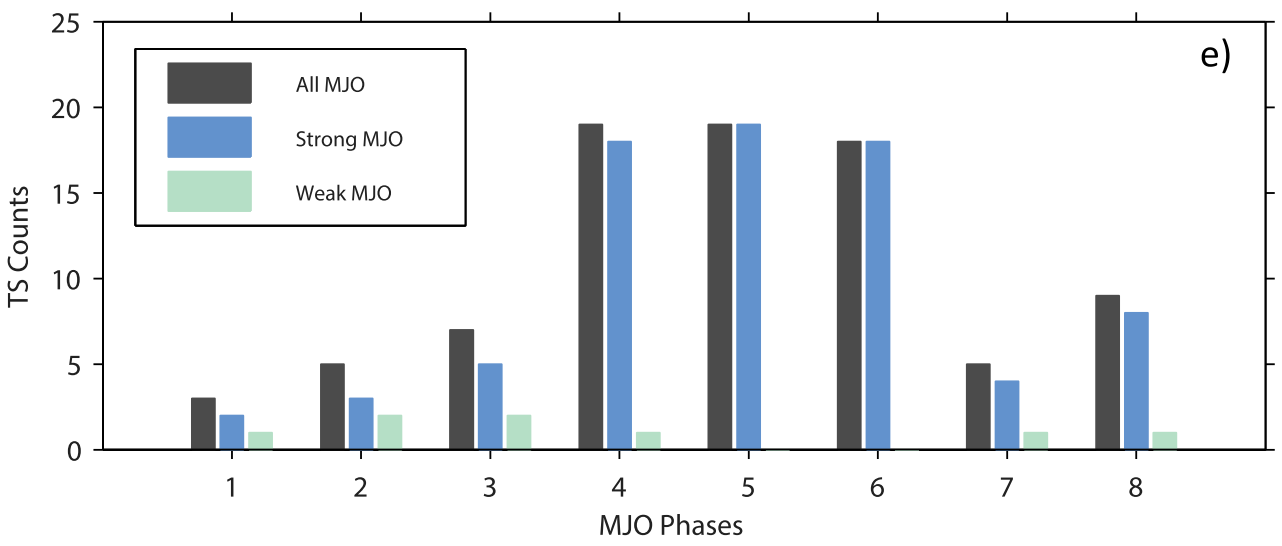

FIG. 7. (a)-(d) Genesis of the more predictable TCs over the WP from 2003 to 2013 during different local MJO phases. Shading represents the observed anomalous rainfall pattern $\left(\mathrm{mm} \mathrm{day}^{-1}\right)$ during each MJO phase. (e) Counts of more predictable TC genesis over the WP as a function of MJO phases under both strong and weak MJO periods. MJO phases shown here are defined based on PCs of the two leading EEOF modes of 10-70-day filtered rainfall over the WP for summers of 2003-13.

could be associated with other large-scale factors, including modulations from synoptic waves. Figure $8 \mathrm{dem}-$ onstrates an example of how these more predictable TCs over the WP are related to cyclonic phases of local TDWs. It is clearly evident that most of these TCs $(\sim 78 \%)$ formed over regions with low-level cyclonic vorticity anomalies along the southeast-northwestward slanted TDW wave trains, in agreement with previous studies on important roles of synoptic waves for TC genesis (e.g., Li and Fu 2006; Chen and Huang 2009; Chen and Chou 2014).

Similarly, a close association between cyclogenesis of the more predictable TCs over the EP and local MJO is also clearly indicated by Fig. 9. These TC geneses are strongly phase-locked to the EP MJO phases, with $87 \%$ of them being formed during MJO phases 3-6, in accord 
a) Phase $2+3$

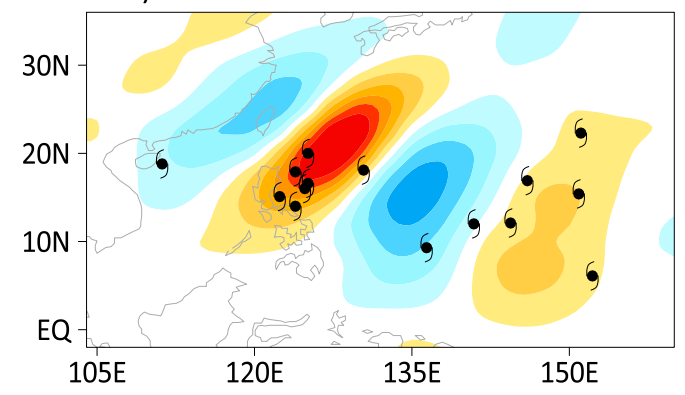

b) Phase $4+5$

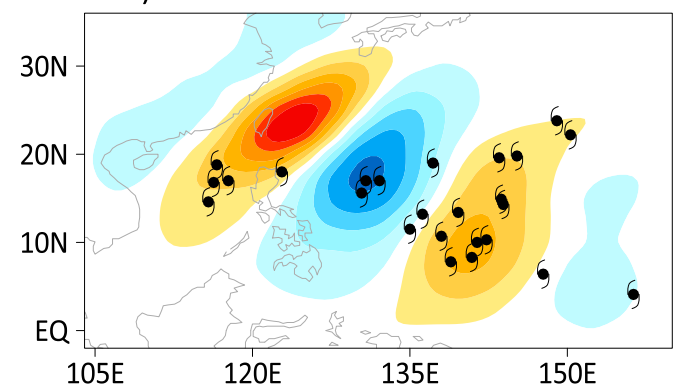

c) Phase 6+7

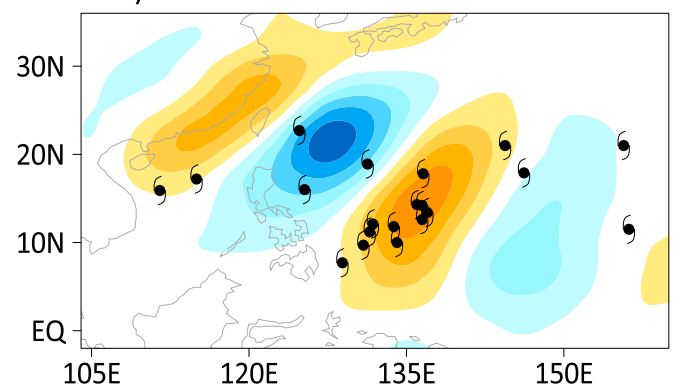

d) Phase $8+1$

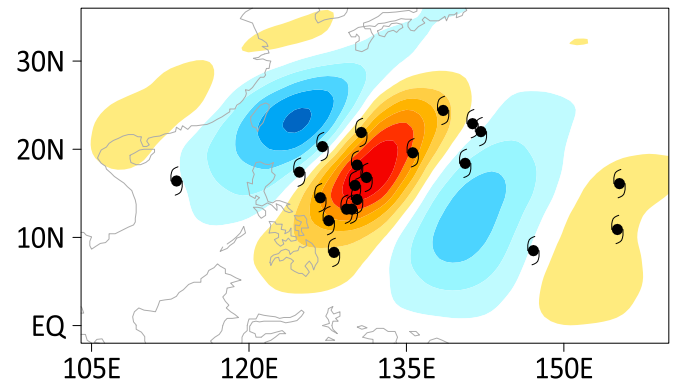

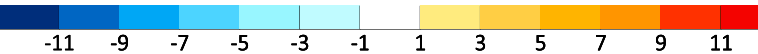

FIG. 8. Locations of more predictable TC geneses over the WP from 2003 to 2013 during different phases of the TDWs over the WP. Shading represents the observed $850-\mathrm{hPa}$ relative vorticity anomalies $\left(10^{-6} \mathrm{~s}^{-1}\right)$ at different TDW phases. TDW phases shown here are defined based on PCs of the two leading EEOF modes of 2-8-day filtered 850-hPa vorticity over the WP for summers of 2003-13.

with previous analyses by Jiang et al. (2012a). Jiang et al. (2012a) illustrated that the genesis potential index (Emanuel and Nolan 2004) anomalies can well depict the observed modulations of cyclogenesis by the EP MJO, with all contributions from lower-level cyclonic vorticity, enhanced midlevel relative humidity, and reduced vertical wind shear during particular MJO phases. On the other hand, much as in the WP, a majority of the more predictable TCs $(\sim 78 \%)$ over the EP tend to be formed over regions of positive $850-\mathrm{hPa}$ relative vorticity anomalies associated with the EP EWs (Fig. 10).

Over the NA, however, the leading QBW mode associated with the West Africa monsoon does not have strong modulations on those more predictable local TC geneses shown in Fig. 5a, even over the eastern NA (figure not shown). Since it has been previously reported that TC activity over the Gulf of Mexico and Caribbean Seas can also be modulated by large-scale circulations associated with the EP MJO (e.g., Maloney and Hartmann 2000b; Barrett and Leslie 2009), the cyclogenesis of these TCs over the Caribbean Seas during different EP MJO phases is also examined in Fig. 9a (green TC marks). While only a very limited number of more predictable TCs are identified over the Caribbean Sea during the 11 years, association of their geneses with the EP MJO phases is not clearly established. Additionally, lack of more predictable TCs over the Gulf of Mexico as shown in Fig. 5 may also indicate a weak impact of the EP MJO on cyclogenesis predictability over this region.

Locations of the more predictable TCs over the NA during different phases of local EWs are also examined. While these more predictable TCs, particularly over the eastern NA, are largely collocated with cyclonic vorticity of the EWs (figure not shown), the generally limited numbers of more predictable TCs over the NA indicate less predictability of cyclogenesis over the NA.

The above analyses suggest that higher cyclogenesis predictive skill for those selected TCs based on the GFDL coupled prediction system could be the result of strong dynamic or thermodynamic forcing associated with the MJO and CCEWs, particularly over the WP and EP. To further illustrate the important role of the MJO on cyclogenesis prediction, predictive skill over the tropical regions of the WP and EP during strong (amplitude of leading PCs $>1$ ) and enhanced local 
a) Phase $2+3$

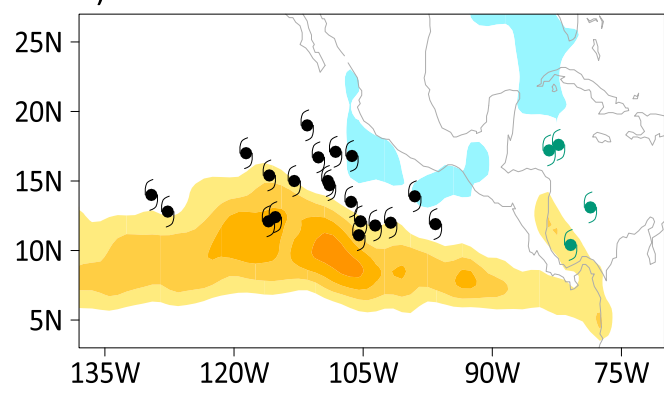

b) Phase $4+5$

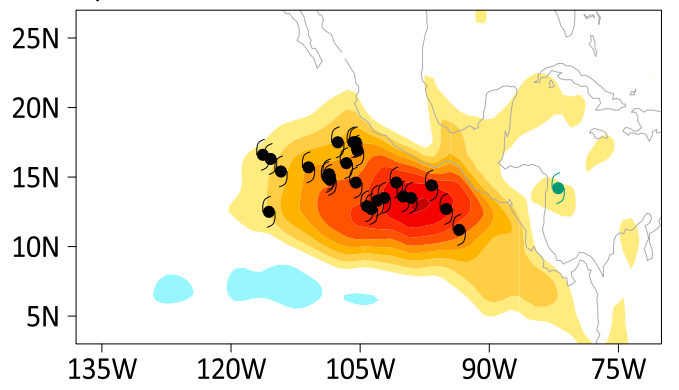

c) Phase $6+7$

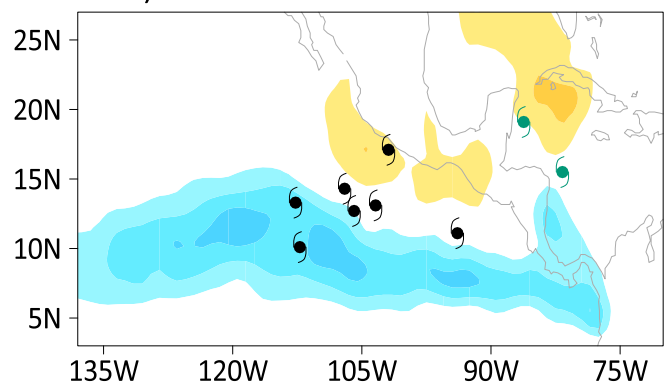

d) Phase $8+1$

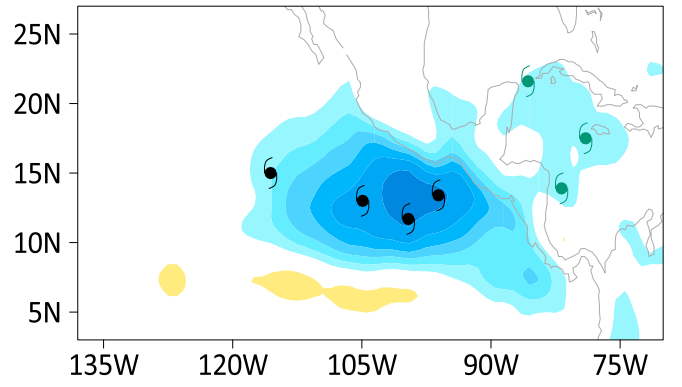

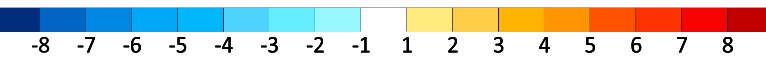

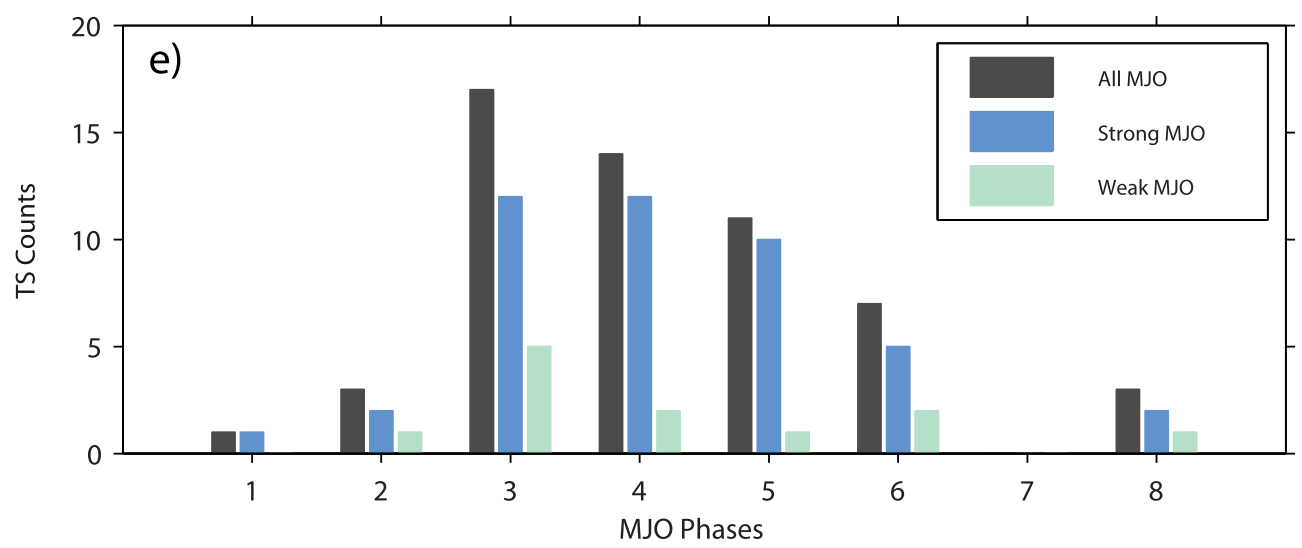

FIG. 9. As in Fig. 7, but for locations of more predictable TCs with local MJO phases over the EP. Genesis of more predictable TCs over NA during different EP MJO phases is also plotted in (a)-(d) using green. MJO phases shown here are defined based on PCs of the two leading EEOF modes of 10-70-day filtered rainfall over the EP for 2003-13 summers.

MJO periods (phases 4-6 for the WP and 3-5 for the EP) and suppressed or weak MJO phases is further examined (Fig. 11). Persistently higher (lower) cyclogenesis predictive skill is clearly seen during strong enhanced (weak or suppressed) MJO phases over the tropical WP and EP up to forecast lead day 12. Predictive skill of about $50 \%$ is evident on forecast lead day 5 for TCs formed during the enhanced strong MJO periods versus $20 \%$ during weak or suppressed MJO phases. The convergence of genesis prediction skill at long lead times shown in Fig. 11 may suggest lack of predictability beyond two weeks.

\section{d. Large-scale predictability and cyclogenesis prediction skill}

Since cyclogenesis predictive skill in this study is defined by agreement among ensemble members in making correct forecasts, it is thus closely linked to 
a) Phase $2+3$

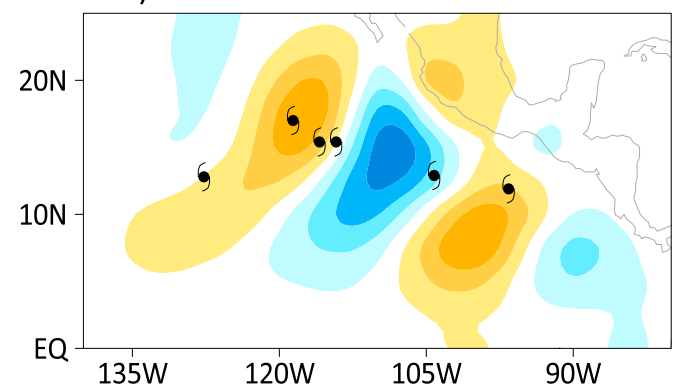

b) Phase $4+5$

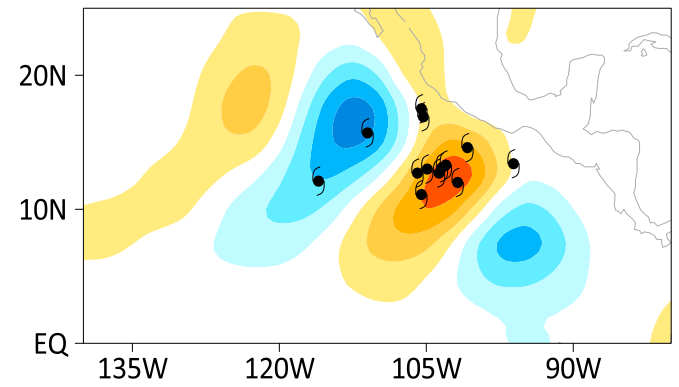

c) Phase $6+7$

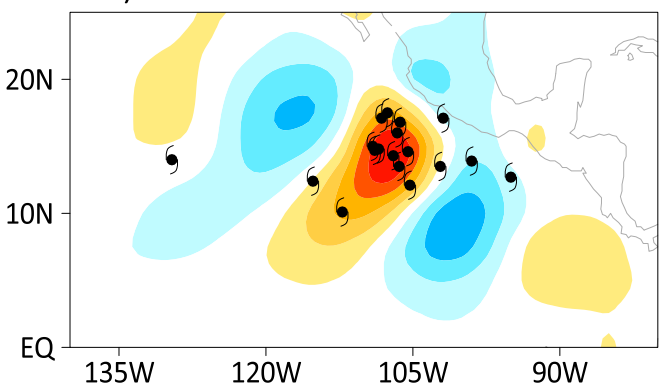

d) Phase $8+1$

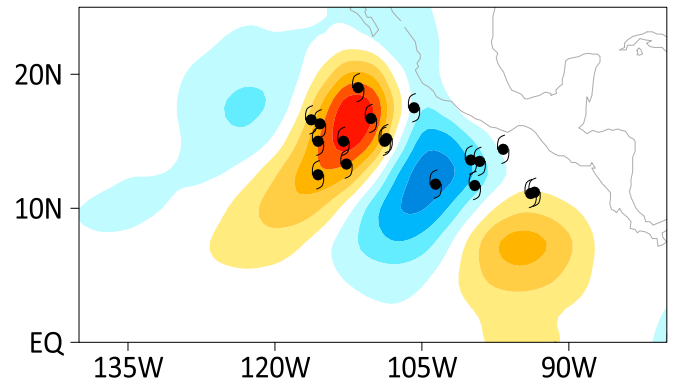

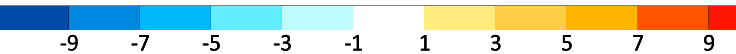

FIG. 10. As in Fig. 8, but for locations of more predictable TCs during the evolution of the EWs over the EP. EW phases shown here are defined based on PCs of the two leading EEOF modes of 2-8-day filtered 850-hPa vorticity over the EP for 2003-13 summers.

predictability of large-scale patterns in this model. Therefore, we further explored predictability of three large-scale variables which are widely recognized as important factors in regulating cyclogenesis (e.g., Emanuel and Nolan 2004), including 850-hPa relative vorticity, vertical shear of $u$ wind between 200 and $850 \mathrm{hPa}$, and 500-hPa specific humidity. ${ }^{5}$ Predictability of each variable on a particular grid is defined as an averaged correlation of temporal series from 330 forecasts initialized on six days of each month between each available pair of ensemble members from the 12 total members and calculated as a function of forecast lead days. With a special interest on the intraseasonal predictability of cyclogenesis, Fig. 12 illustrates predictability of the three variables for hindcasts during week 2 (days 8-14). Regions with higher predictability of all these variables are largely confined in the tropics. Particularly noteworthy is higher predictability in 850 -hPa relative vorticity over the Indian Ocean, the

\footnotetext{
${ }^{5}$ Since only the specific humidity field at $500 \mathrm{hPa}$ was archived from hindcasts, $500-\mathrm{hPa}$ specific humidity is used instead of that at $600 \mathrm{hPa}$, which has been more commonly used to represent lowerto-middle tropospheric moisture in previous studies.
}

northern WP, the EP warm pool, and a slightly slanted belt over the tropical NA, exhibiting a great resemblance to cyclogenesis locations for the more predictable TCs in Fig. 5a. ${ }^{6}$ Generally weaker predictability of these large-scale variables over the NA is also consistent with weaker cyclogenesis predictive skill over this region. Meanwhile, very low predictability of all these three variables is found over the Gulf of Mexico and to the north of the Bahamas, in agreement with rather limited cyclogenesis skill over these regions as shown in Fig. 5a. Note that spatial patterns of these three large-scale factors, particularly the $850-\mathrm{hPa}$ relative vorticity, are largely in accord with active regions of the MJO and CCEWs. Therefore, results shown in Fig. 12 largely support the notion widely recognized in the community that the MJO and CCEWs play a critical role to serve as a primary predictability source for intraseasonal prediction of extreme weather events (e.g., Waliser 2006; National Academies of Sciences 2016; Vitart et al. 2017), such as TC activity as explored in this study.

\footnotetext{
${ }^{6}$ Note that cyclogenesis is favored away from the equator to facilitate rotation by the Coriolis force.
} 


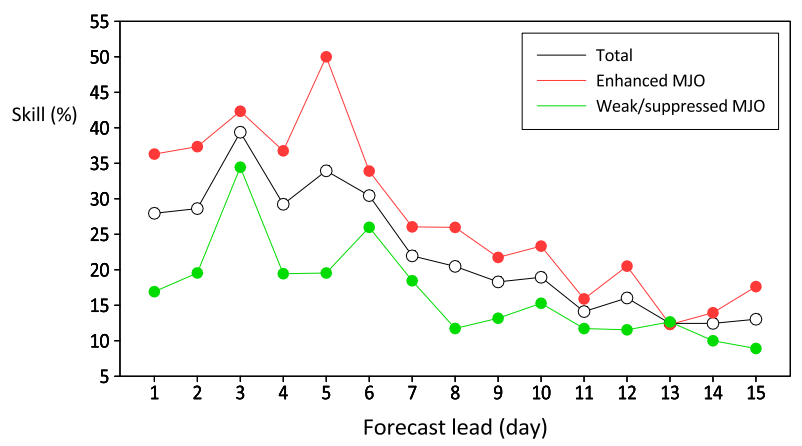

FIG. 11. Cyclogenesis predictive skill averaged for all TCs in the tropical WP and EP from 2003 to 2013 as a function of forecast lead time (black) and for TCs that formed during local active (phases 4-6 for the WP and 3-5 for the EP) strong MJO periods (red) and weak or suppressed MJO periods (green). Definitions of tropical WP and EP can be found in the Fig. 3 caption.

\section{Summary and discussion}

Recent advances in modeling and forecasting the Madden-Julian oscillation (MJO) and implementation of high-resolution grids in global models make it possible to explicitly resolve tropical cyclone (TC) activity and its interaction with the MJO, justifying dynamical TC predictions beyond the weather time scale. Motivated by increasing demand in the community for intraseasonal predictions of weather extremes, intraseasonal predictability of cyclogenesis is investigated in this study based on a recently updated coupled model system at NOAA's GFDL. This study extends a previous study by Xiang et al. (2015a), which focused on two severe hurricane/ typhoon events, Sandy (2012) and Haiyan (2013), by analyzing about 600 tropical storms over global oceans during 11 summer seasons.

While this coupled model system is able to reasonably represent the climatological TC genesis probability distribution, genesis prediction skill averaged over all these about 600 TCs is rather limited compared to that for Sandy and Haiyan with a very high false alarm rate. In agreement with several previous studies, slightly higher predictive skill is found over the WP and EP than over the NA. It is illustrated that TCs with relatively higher genesis predictive skill are largely formed over tropical oceans where the MJO and convectively coupled equatorial waves (CCEWs) are active. Meanwhile, genesis locations of these more predictable TCs tend to be strongly phase-locked to the convectively active region of the MJO as well as regions of low-level cyclonic vorticity associated with the tropical depression-type waves (TDWs) or easterly waves (EWs), particularly over the WP and EP. Higher cyclogenesis prediction skill in general is found for
TCs that formed during the strong enhanced periods of the MJO than those during weak or suppressed MJO periods. All these results confirm the previous notion that the MJO and tropical synoptic waves play a critical role for intraseasonal TC forecasts by serving as important predictability sources.

It is further illustrated that cyclogenesis prediction skill in the GFDL coupled model is closely associated with model predictability of large-scale patterns. Particularly over the NA, higher predictability of low-level relative vorticity, midlevel humidity, and vertical shear of zonal wind is found along a slightly slanted belt from the West Africa coast to the Caribbean Sea, in accord with more predictable cyclogenesis over this region. In contrast, rather limited predictability of these largescale variables over the Gulf of Mexico and north of Bahamas is also consistent with poor cyclogenesis predictive skill in these areas. The weak influences from tropical climate regimes could partially explain lower predictability of large-scale variables over the NA, as also indicated by recent analyses of hindcasts from the NOAA GEFS (Wang et al. 2018).

One of the main objectives of this study is to comprehensively assess predictive skill of tropical cyclogenesis in a recently developed coupled model system, and thus to explore the potential for intraseasonal dynamical prediction of TC genesis. While we illustrate that relatively skillful TC genesis in this model is closely associated with large-scale forcing by the MJO and synoptic waves, detailed physical processes responsible for model TC genesis remain unclear and warrant further detailed investigations. For example, what are the key large-scale factors of the MJO and CCEWs that play critical roles in modulating TC genesis? Although many models exhibit skillful predictions of the MJO (3-4 weeks) as measured by the Wheeler-Hendon index, intraseasonal prediction of critical physical processes associated with the MJO for TC genesis, such as the low-level vorticity and midlevel moisture fields, could still be very challenging. This may explain the significant gap between the prediction skill for the MJO and tropical cyclogenesis. On the other hand, only TDWs and EWs are examined in this study to explore impacts of tropical synoptic waves on TC genesis predictive skill. The role of other CCEWs, including equatorial Rossby, mixed Rossby-gravity, and inertia-gravity waves, with regard to model TC genesis needs to be further characterized. While predictability of the MJO has been widely explored in the community, studies on intraseasonal predictability of these CCEWs remain limited.

Moreover, the initial condition of this prediction system is generated by a simple nudging method rather than by an assimilation approach as in operational prediction 
a) $850 \mathrm{hPa}$ vorticity

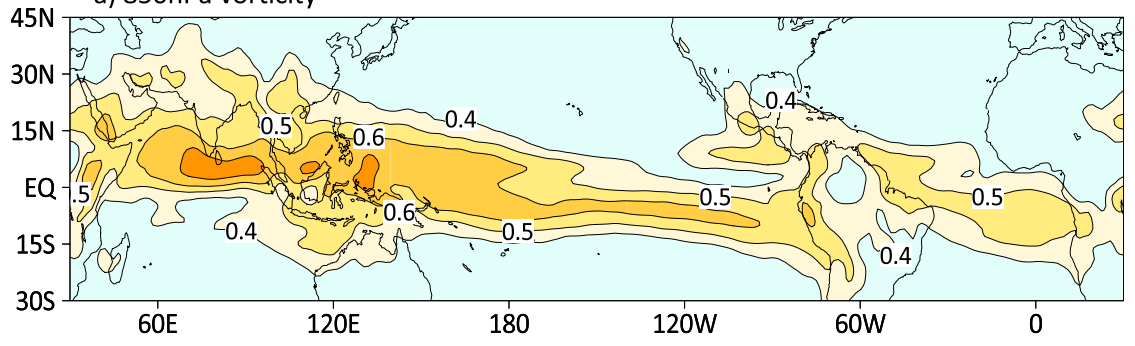

b) vertical u-wind shear

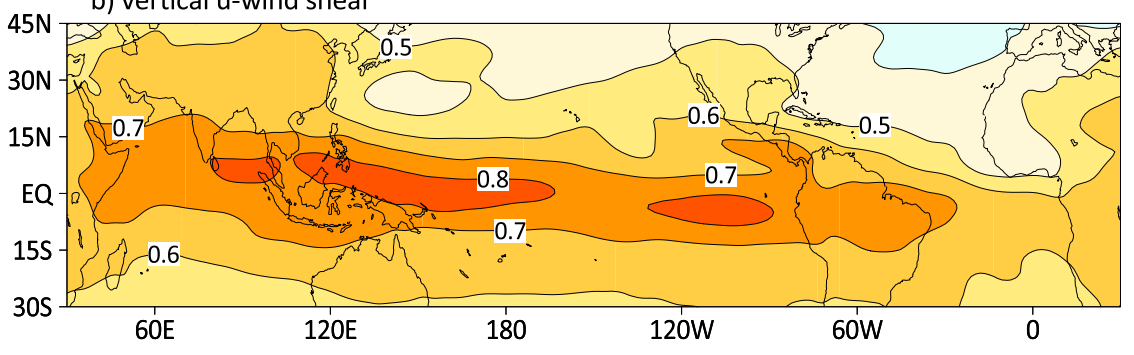

c) $500 \mathrm{hPa}$ specific humidity

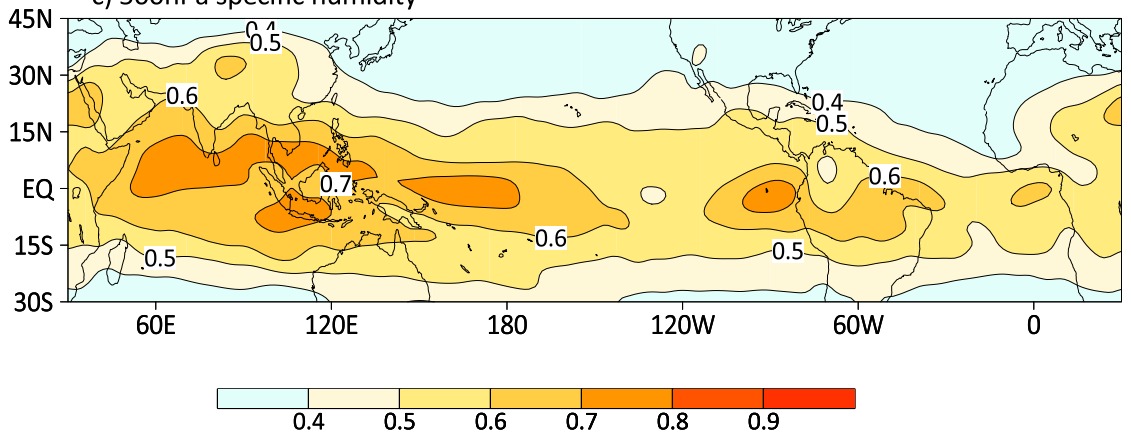

FIG. 12. Predictability of large-scale factors, including (a) 850-hPa vorticity, (b) 200-850-hPa vertical $u$-wind shear, and (c) $500-\mathrm{hPa}$ specific humidity, estimated based on consistency (correlations) among 12 ensemble member forecasts during boreal summer (June-November). See text for details in deriving these predictability patterns.

systems. Also, hindcast ensemble members in this study are constructed by applying slightly time-lagged initial conditions rather than by perturbing initial conditions with realistic uncertainties in the initial condition and model physics. How initial conditions and ensemble schemes affect intraseasonal predictability of the TC genesis will need to be examined in a future study, for example, based on hindcasts from the ECWMF-IFS and the Next Generation Global Prediction System (NGGPS) that is currently under development.

Acknowledgments. We are grateful for the insightful comments from Drs. K. Gao and N. Johnson and from anonymous reviewers, which led to substantial improvement of this manuscript. We acknowledge support by the NOAA Climate Program Office (CPO) under Award
NA12OAR4310075. XJ was also supported by NOAA CPO Awards NA15OAR4310098, NA15OAR4310177, and NA17OAR4310261. BX and MZ were partially supported by NOAA CPO Award GC14-252. TL was supported by ONR Grant N00014-16-12260. ZW was supported by NOAA Awards NA16OAR4310080 and NA15NWS4680007 and NRL Grant N00173-15-1-G004.

\section{REFERENCES}

Agudelo, P. A., C. D. Hoyos, P. J. Webster, and J. A. Curry, 2009: Application of a serial extended forecast experiment using the ECMWF model to interpret the predictive skill of tropical intraseasonal variability. Climate Dyn., 32, 855-872, https:// doi.org/10.1007/s00382-008-0447-x.

Ahn, M.-S., D. Kim, K. R. Sperber, I.-S. Kang, E. Maloney, D. Waliser, and H. Hendon, 2017: MJO simulation in CMIP5 
climate models: MJO skill metrics and process-oriented diagnosis. Climate Dyn., 49, 4023-4045, https://doi.org/10.1007/ s00382-017-3558-4.

Barrett, B. S., and L. M. Leslie, 2009: Links between tropical cyclone activity and Madden-Julian oscillation phase in the North Atlantic and northeast Pacific basins. Mon. Wea. Rev., 137, 727-744, https://doi.org/10.1175/2008MWR2602.1.

Bechtold, P., M. Köhler, T. Jung, F. Doblas-Reyes, M. Leutbecher, M. J. Rodwell, F. Vitart, and G. Balsamo, 2008: Advances in simulating atmospheric variability with the ECMWF model: From synoptic to decadal time-scales. Quart. J. Roy. Meteor. Soc., 134, 1337-1351, https://doi.org/10.1002/ qj.289.

Belanger, J. I., J. A. Curry, and P. J. Webster, 2010: Predictability of North Atlantic tropical cyclone activity on intraseasonal time scales. Mon. Wea. Rev., 138, 4362-4374, https://doi.org/ 10.1175/2010MWR3460.1.

, P. J. Webster, J. A. Curry, and M. T. Jelinek, 2012: Extended prediction of north Indian Ocean tropical cyclones. Wea. Forecasting, 27, 757-769, https://doi.org/10.1175/WAF-D-11-00083.1.

Bessafi, M., and M. C. Wheeler, 2006: Modulation of south Indian Ocean tropical cyclones by the Madden-Julian oscillation and convectively coupled equatorial waves. Mon. Wea. Rev., 134, 638-656, https://doi.org/10.1175/MWR3087.1.

Bretherton, C. S., J. R. McCaa, and H. Grenier, 2004: A new parameterization for shallow cumulus convection and its application to marine subtropical cloud-topped boundary layers. Part I: Description and 1D results. Mon. Wea. Rev., 132, 864-882, https:// doi.org/10.1175/1520-0493(2004)132<0864:ANPFSC > 2.0.CO;2.

Camargo, S. J., M. C. Wheeler, and A. H. Sobel, 2009: Diagnosis of the MJO modulation of tropical cyclogenesis using an empirical index. J. Atmos. Sci., 66, 3061-3074, https://doi.org/ 10.1175/2009JAS3101.1.

Cao, X., T. Li, M. Peng, W. Chen, and G. Chen, 2014: Effects of monsoon trough intraseasonal oscillation on tropical cyclogenesis over the western North Pacific. J. Atmos. Sci., 71, 4639-4660, https://doi.org/10.1175/JAS-D-13-0407.1.

Chen, G., and R. Huang, 2009: Interannual variations in mixed Rossby-gravity waves and their impacts on tropical cyclogenesis over the western North Pacific. J. Climate, 22, 535-549, https://doi.org/10.1175/2008JCLI2221.1.

- , and C. Chou, 2014: Joint contribution of multiple equatorial waves to tropical cyclogenesis over the western North Pacific. Mon. Wea. Rev., 142, 79-93, https://doi.org/10.1175/ MWR-D-13-00207.1.

Davis, C. A., D. A. Ahijevych, W. Wang, and W. C. Skamarock, 2016: Evaluating medium-range tropical cyclone forecasts in uniform- and variable-resolution global models. Mon. Wea. Rev., 144, 4141-4160, https://doi.org/10.1175/MWR-D-16-0021.1.

Dee, D. P., and Coauthors, 2011: The ERA-Interim reanalysis: Configuration and performance of the data assimilation system. Quart. J. Roy. Meteor. Soc., 137, 553-597, https://doi.org/10.1002/ qj. 828.

Dickinson, M., and J. Molinari, 2002: Mixed Rossby-gravity waves and western Pacific tropical cyclogenesis. Part I: Synoptic evolution. J. Atmos. Sci., 59, 2183-2196, https://doi.org/10.1175/ 1520-0469(2002)059<2183:MRGWAW >2.0.CO;2.

Dunkerton, T. J., M. T. Montgomery, and Z. Wang, 2009: Tropical cyclogenesis in a tropical wave critical layer: Easterly waves. Atmos. Chem. Phys., 9, 5587-5646, https://doi.org/10.5194/ acp-9-5587-2009.

Elsberry, R. L., M. S. Jordan, and F. Vitart, 2010: Predictability of tropical cyclone events on intraseasonal timescales with the
ECMWF monthly forecast model. Asia-Pac. J. Atmos. Sci., 46, 135-153, https://doi.org/10.1007/s13143-010-0013-4.

—, H.-C. Tsai, and M. S. Jordan, 2014: Extended-range forecasts of Atlantic tropical cyclone events during 2012 using the ECMWF 32-day ensemble predictions. Wea. Forecasting, 29, 271-288, https://doi.org/10.1175/WAF-D-13-00104.1.

Emanuel, K. A., and D. S. Nolan, 2004: Tropical cyclone activity and global climate. 26th Conf. on Hurricanes and Tropical Meteorology, Miami, FL, Amer. Meteor. Soc., 10A.2, https:// ams.confex.com/ams/pdfpapers/75463.pdf.

Frank, W. M., and P. E. Roundy, 2006: The role of tropical waves in tropical cyclogenesis. Mon. Wea. Rev., 134, 2397-2417, https:// doi.org/10.1175/MWR3204.1.

Fu, B., T. Li, M. S. Peng, and F. Weng, 2007: Analysis of tropical cyclogenesis in the western North Pacific for 2000 and 2001. Wea. Forecasting, 22, 763-780, https://doi.org/10.1175/ WAF1013.1.

Gall, J. S., I. Ginis, S.-J. Lin, T. P. Marchok, and J.-H. Chen, 2011: Experimental tropical cyclone prediction using the GFDL 25-km-resolution global atmospheric model. Wea. Forecasting, 26, 1008-1019, https://doi.org/10.1175/WAF-D-10-05015.1.

Goldenberg, S. B., and L. J. Shapiro, 1996: Physical mechanisms for the association of El Niño and West African rainfall with Atlantic major hurricane activity. J. Climate, $\mathbf{9}$, 1169-1187, https://doi.org/10.1175/1520-0442(1996)009<1169: PMFTAO $>2.0 . \mathrm{CO} ; 2$.

Gray, W. M., 1984: Atlantic seasonal hurricane frequency. Part I: El Niño and $30 \mathrm{mb}$ quasi-biennial oscillation influences. Mon. Wea. Rev., 112, 1649-1668, https://doi.org/10.1175/ 1520-0493(1984)112<1649:ASHFPI >2.0.CO;2.

Halperin, D. J., H. E. Fuelberg, R. E. Hart, J. H. Cossuth, P. Sura, and R. J. Pasch, 2013: An evaluation of tropical cyclone genesis forecasts from global numerical models. Wea. Forecasting, 28, 1423-1445, https://doi.org/10.1175/WAF-D-13-00008.1.

,,--- , and $\longrightarrow, 2016$ : Verification of tropical cyclone genesis forecasts from global numerical models: Comparisons between the North Atlantic and eastern North Pacific basins. Wea. Forecasting, 31, 947-955, https://doi.org/10.1175/ WAF-D-15-0157.1.

Harris, L. M., S.-J. Lin, and C. Tu, 2016: High-resolution climate simulations using GFDL HiRAM with a stretched global grid. J. Climate, 29, 4293-4314, https://doi.org/10.1175/ JCLI-D-15-0389.1.

Hendon, H. H., B. Liebmann, M. Newman, J. D. Glick, and J. E. Schemm, 2000: Medium-range forecast errors associated with active episodes of the Madden-Julian oscillation. Mon. Wea. Rev., 128, 69-86, https://doi.org/10.1175/1520-0493(2000)128<0069: MRFEAW $>2.0 . \mathrm{CO} ; 2$.

Hsu, H.-H., C.-H. Weng, and C.-H. Wu, 2004: Contrasting characteristics between the northward and eastward propagation of the intraseasonal oscillation during the boreal summer. J. Climate, 17, 727-743, https://doi.org/10.1175/ 1520-0442(2004)017<0727:CCBTNA > 2.0.CO;2.

Huang, P., C. Chou, and R. Huang, 2011: Seasonal modulation of tropical intraseasonal oscillations on tropical cyclone geneses in the western North Pacific. J. Climate, 24, 6339-6352, https:// doi.org/10.1175/2011JCLI4200.1.

Huffman, G. J., and Coauthors, 2007: The TRMM Multisatellite Precipitation Analysis (TMPA): Quasi-global, multiyear, combined-sensor precipitation estimates at fine scales. $J$. Hydrometeor., 8, 38-55, https://doi.org/10.1175/JHM560.1.

Hung, M.-P., J.-L. Lin, W. Wang, D. Kim, T. Shinoda, and S. J. Weaver, 2013: MJO and convectively coupled equatorial 
waves simulated by CMIP5 climate models. J. Climate, 26, 6185-6214, https://doi.org/10.1175/JCLI-D-12-00541.1.

Jiang, X., 2017: Key processes for the eastward propagation of the Madden-Julian oscillation based on multimodel simulations. J. Geophys. Res. Atmos., 122, 755-770, https://doi.org/10.1002/ 2016JD025955.

— , T. Li, and B. Wang, 2004: Structures and mechanisms of the northward propagating boreal summer intraseasonal oscillation. J. Climate, 17, 1022-1039, https://doi.org/10.1175/ 1520-0442(2004)017<1022:SAMOTN $>2.0 . \mathrm{CO} ; 2$.

— D. E. Waliser, M. C. Wheeler, C. Jones, M.-I. Lee, and S. D. Schuert, 2008: Assessing the skill of an all-season statistical forecast model for the Madden-Julian oscillation. Mon. Wea. Rev., 136, 1940-1956, https://doi.org/10.1175/2007MWR2305.1.

_ M. Zhao, and D. E. Waliser, 2012a: Modulation of tropical cyclones over the eastern Pacific by the intraseasonal variability simulated in an AGCM. J. Climate, 25, 6524-6538, https://doi.org/10.1175/JCLI-D-11-00531.1.

_ and Coauthors, 2012b: Simulation of the intraseasonal variability over the eastern Pacific ITCZ in climate models. Climate Dyn., 39, 617-636, https://doi.org/10.1007/s00382-011-1098-x.

_ , E. D. Maloney, J.-L. F. Li, and D. E. Waliser, 2013: Simulations of the eastern North Pacific intraseasonal variability in CMIP5 GCMs. J. Climate, 26, 3489-3510, https://doi.org/ 10.1175/JCLI-D-12-00526.1.

— , T. L. Kubar, S. Wong, W. S. Olson, and D. E. Waliser, 2014: Modulation of marine low clouds associated with the tropical intraseasonal variability over the eastern Pacific. J. Climate, 27, 5560-5574, https://doi.org/10.1175/JCLI-D-13-00569.1.

_ cesses of the Madden-Julian oscillation: Exploring key model physics in climate simulations. J. Geophys. Res. Atmos., 120, 4718-4748, https://doi.org/10.1002/2014JD022375.

Jones, C., L. M. V. Carvalho, R. W. Higgins, D. E. Waliser, and J.-K. E. Schemm, 2004: A statistical forecast model of tropical intraseasonal convective anomalies. J. Climate, 17, 2078-2095, https://doi.org/10.1175/1520-0442(2004)017<2078: ASFMOT $>2.0 . \mathrm{CO} ; 2$.

Kiladis, G. N., M. C. Wheeler, P. T. Haertel, K. H. Straub, and P. E. Roundy, 2009: Convectively coupled equatorial waves. Rev. Geophys., 47, RG2003, https://doi.org/10.1029/ 2008RG000266; Corrigendum, 49, RG3004, https://doi.org/ 10.1029/2011RG000370.

Klotzbach, P. J., 2010: On the Madden-Julian oscillation-Atlantic hurricane relationship. J. Climate, 23, 282-293, https://doi.org/ 10.1175/2009JCLI2978.1.

Knapp, K. R., M. C. Kruk, D. H. Levinson, H. J. Diamond, and C. J. Neumann, 2010: The International Best Track Archive for Climate Stewardship (IBTrACS). Bull. Amer. Meteor. Soc., 91, 363-376, https://doi.org/10.1175/2009BAMS2755.1.

Komaromi, W. A., and S. J. Majumdar, 2014: Ensemble-based error and predictability metrics associated with tropical cyclogenesis. Part I: Basinwide perspective. Mon. Wea. Rev., 142, 2879-2898, https://doi.org/10.1175/MWR-D-13-00370.1.

Lau, K.-H., and N.-C. Lau, 1990: Observed structure and propagation characteristics of tropical summertime synoptic scale disturbances. Mon. Wea. Rev., 118, 1888-1913, https://doi.org/ 10.1175/1520-0493(1990)118<1888:OSAPCO > 2.0.CO;2.

Lau, W. K.-M., and D. E. Waliser, 2012: Intraseasonal Variability in the Atmosphere-Ocean Climate System. 2nd ed. Springer, 614 pp.

Lee, C.-Y., S. J. Camargo, F. Vitart, A. H. Sobel, and M. K. Tippett, 2018: Sub-seasonal tropical cyclone genesis prediction and
MJO in the S2S dataset. Wea. Forecasting, https://doi.org/ 10.1175/waf-d-17-0165.1, in press.

Lee, J.-Y., B. Wang, M. C. Wheeler, X. Fu, D. E. Waliser, and I.-S. Kang, 2013: Real-time multivariate indices for the boreal summer intraseasonal oscillation over the Asian summer monsoon region. Climate Dyn., 40, 493-509, https://doi.org/ 10.1007/s00382-012-1544-4.

Lee, S.-S., B. Wang, D. E. Waliser, J. M. Neena, and J.-Y. Lee, 2015: Predictability and prediction skill of the boreal summer intraseasonal oscillation in the Intraseasonal Variability Hindcast Experiment. Climate Dyn., 45, 2123-2135, https:// doi.org/10.1007/s00382-014-2461-5.

Leroy, A., and M. C. Wheeler, 2008: Statistical prediction of weekly tropical cyclone activity in the Southern Hemisphere. Mon. Wea. Rev., 136, 3637-3654, https://doi.org/10.1175/ 2008MWR2426.1.

Li, R. C. Y., and W. Zhou, 2013: Modulation of western North Pacific tropical cyclone activity by the ISO. Part I: Genesis and intensity. J. Climate, 26, 2904-2918, https://doi.org/10.1175/ JCLI-D-12-00210.1.

Li, T., 2006: Origin of the summertime synoptic-scale wave train in the western North Pacific. J. Atmos. Sci., 63, 1093-1102, https://doi.org/10.1175/JAS3676.1.

_ 2012: Synoptic and climatic aspects of tropical cyclogenesis in western North Pacific. Cyclones: Formation, Triggers and Control, K. Oouchi and H. Fudeyasu, Eds., Nova Science Publishers, Inc., 61-94.

, and B. Fu, 2006: Tropical cyclogenesis associated with Rossby wave energy dispersion of a preexisting typhoon. Part I: Satellite data analyses. J. Atmos. Sci., 63, 1377-1389, https:// doi.org/10.1175/JAS3692.1.

一 - — X. Xe, B. Wang, and M. Peng, 2003: Satellite data analysis and numerical simulation of tropical cyclone formation. Geophys. Res. Lett., 30, 2122, https://doi.org/10.1029/ 2003 GL018556.

Li, W., Z. Wang, and M. S. Peng, 2016: Evaluating tropical cyclone forecasts from the NCEP Global Ensemble Forecasting System (GEFS) Reforecast version 2. Wea. Forecasting, 31, 895916, https://doi.org/10.1175/WAF-D-15-0176.1.

Liebmann, B., H. H. Hendon, and J. D. Glick, 1994: The relationship between tropical cyclones of the western Pacific and Indian Oceans and the Madden-Julian oscillation. J. Meteor. Soc. Japan, 72, 401-412, https://doi.org/10.2151/ jmsj1965.72.3_401.

Lin, H., G. Brunet, and J. Derome, 2008: Forecast skill of the Madden-Julian oscillation in two Canadian atmospheric models. Mon. Wea. Rev., 136, 4130-4149, https://doi.org/10.1175/ 2008MWR2459.1.

Madden, R. A., and P. R. Julian, 1994: Observations of the 40-50-day tropical oscillation-A review. Mon. Wea. Rev., 122, 814-837, https://doi.org/10.1175/1520-0493(1994)122<0814: OOTDTO $>2.0 . \mathrm{CO} ; 2$.

Maloney, E. D., and D. L. Hartmann, 2000a: Modulation of eastern North Pacific hurricanes by the Madden-Julian oscillation. J. Climate, 13, 1451-1460, https://doi.org/10.1175/ 1520-0442(2000)013<1451:MOENPH>2.0.CO;2.

— and - 2000b: Modulation of hurricane activity in the Gulf of Mexico by the Madden-Julian oscillation. Science, 287, 2002-2004, https://doi.org/10.1126/science.287.5460.2002.

Mao, J., and G. Wu, 2010: Intraseasonal modulation of tropical cyclogenesis in the western North Pacific: A case study. Theor. Appl. Climatol., 100, 397-411, https://doi.org/10.1007/ s00704-009-0195-9. 
McTaggart-Cowan, R., T. J. Galarneau Jr., L. F. Bosart, R. W. Moore, and O. Martius, 2013: A global climatology of baroclinically influenced tropical cyclogenesis. Mon. Wea. Rev., 141, 1963-1989, https://doi.org/10.1175/MWR-D-12-00186.1.

Molteni, F., R. Buizza, T. N. Palmer, and T. Petroliagis, 1996: The ECMWF ensemble prediction system: Methodology and validation. Quart. J. Roy. Meteor. Soc., 122, 73-119, https:// doi.org/10.1002/qj.49712252905.

Mounier, F., and S. Janicot, 2004: Evidence of two independent modes of convection at intraseasonal timescale in the West African summer monsoon. Geophys. Res. Lett., 31, L16116, https://doi.org/10.1029/2004GL020665.

— - — , and G. N. Kiladis, 2008: The West African monsoon dynamics. Part III: The quasi-biweekly zonal dipole. J. Climate, 21, 1911-1928, https://doi.org/10.1175/2007JCLI1706.1.

National Academies of Sciences, 2016: Next Generation Earth System Prediction: Strategies for Subseasonal to Seasonal Forecasts. National Academies Press, 290 pp.

Neena, J. M., X. Jiang, D. E. Waliser, J.-Y. Lee, and B. Wang, 2014a: Eastern Pacific intraseasonal variability: A predictability perspective. J. Climate, 27, 8869-8883, https://doi.org/ 10.1175/JCLI-D-14-00336.1.

, J.-Y. Lee, D. E. Waliser, B. Wang, and X. Jiang, 2014b: Predictability of the Madden-Julian oscillation in the Intraseasonal Variability Hindcast Experiment (ISVHE). J. Climate, 27, 4531-4543, https://doi.org/10.1175/JCLI-D-13-00624.1.

—, D. E. Waliser, and X. Jiang, 2017: Model performance metrics and process diagnostics for boreal summer intraseasonal variability. Climate Dyn., 48, 1661-1683, https:// doi.org/10.1007/s00382-016-3166-8.

Putman, W. M., and S.-J. Lin, 2007: Finite-volume transport on various cubed-sphere grids. J. Comput. Phys., 227, 55-78, https://doi.org/10.1016/j.jcp.2007.07.022.

Rashid, H. A., H. H. Hendon, M. C. Wheeler, and O. Alves, 2011: Prediction of the Madden-Julian oscillation with the POAMA dynamical prediction system. Climate Dyn., 36, 649-661, https://doi.org/10.1007/s00382-010-0754-x.

Reynolds, R. W., T. M. Smith, C. Liu, D. B. Chelton, K. S. Casey, and M. G. Schlax, 2007: Daily high-resolution-blended analyses for sea surface temperature. J. Climate, 20, 5473-5496, https://doi.org/10.1175/2007JCLI1824.1.

Seo, K.-H., J.-K. E. Schemm, C. Jones, and S. Moorthi, 2005: Forecast skill of the tropical intraseasonal oscillation in the NCEP GFS dynamical extended range forecasts. Climate Dyn., 25, 265-284, https://doi.org/10.1007/s00382-005-0035-2.

Serra, Y. L., X. Jiang, B. Tian, J. Amador-Astua, E. D. Maloney, and G. N. Kiladis, 2014: Tropical intraseasonal modes of the atmosphere. Annu. Rev. Environ. Resour., 39, 189-215, https:// doi.org/10.1146/annurev-environ-020413-134219.

Slade, S. A., and E. D. Maloney, 2013: An intraseasonal prediction model of Atlantic and east Pacific tropical cyclone genesis. Mon. Wea. Rev., 141, 1925-1942, https://doi.org/10.1175/ MWR-D-12-00268.1.

Sobel, A. H., and C. S. Bretherton, 1999: Development of synopticscale disturbances over the summertime tropical northwest Pacific. J. Atmos. Sci., 56, 3106-3127, https://doi.org/10.1175/ 1520-0469(1999)056<3106:DOSSDO > 2.0.CO;2.

Toth, Z., and E. Kalnay, 1997: Ensemble forecasting at NCEP and the breeding method. Mon. Wea. Rev., 125, 3297-3319, https://doi.org/10.1175/1520-0493(1997)125<3297: EFANAT $>2.0 . \mathrm{CO} ; 2$

Tsai, H.-C., R. L. Elsberry, M. S. Jordan, and F. Vitart, 2013: Objective verifications and false alarm analyses of western North
Pacific tropical cyclone event forecasts by the ECMWF 32-day ensemble. Asia-Pac. J. Atmos. Sci., 49, 409-420, https://doi.org/ 10.1007/s13143-013-0038-6.

Van der Grijn, G., J. E. Paulsen, F. Lalaurette, and M. Leutbecher, 2004: Early medium-range forecasts of tropical cyclones. ECMWF Newsletter, No. 102, ECMWF, Reading, United Kingdom, 7-14.

Vecchi, G. A., and Coauthors, 2014: On the seasonal forecasting of regional tropical cyclone activity. J. Climate, 27, 7994-8016, https://doi.org/10.1175/JCLI-D-14-00158.1.

Ventrice, M. J., C. D. Thorncroft, and P. E. Roundy, 2011: The Madden-Julian oscillation's influence on African easterly waves and downstream tropical cyclogenesis. Mon. Wea. Rev., 139, 2704-2722, https://doi.org/10.1175/ MWR-D-10-05028.1.

_,- , and C. J. Schreck III, 2012: Impacts of convectively coupled Kelvin waves on environmental conditions for Atlantic tropical cyclogenesis. Mon. Wea. Rev., 140, 2198-2214, https://doi.org/10.1175/MWR-D-11-00305.1.

Vitart, F., 2009: Impact of the Madden Julian oscillation on tropical storms and risk of landfall in the ECMWF forecast system. Geophys. Res. Lett., 36, L15802, https://doi.org/ 10.1029/2009GL039089.

- 2010: TC activity on intraseasonal time scales. Seventh Int. Workshop on Tropical Cyclones, Saint-Gilles-Les-Bains, France, WMO, 3.1.1-3.1.17.

— and F. Molteni, 2010: Simulation of the Madden-Julian oscillation and its teleconnections in the ECMWF forecast system. Quart. J. Roy. Meteor. Soc., 136, 842-855, https://doi.org/ 10.1002/qj.623.

— S. Woolnough, M. A. Balmaseda, and A. M. Tompkins, 2007: Monthly forecast of the Madden-Julian oscillation using a coupled GCM. Mon. Wea. Rev., 135, 2700-2715, https://doi.org/ 10.1175/MWR3415.1.

— A. Leroy, and M. C. Wheeler, 2010: A comparison of dynamical and statistical predictions of weekly tropical cyclone activity in the Southern Hemisphere. Mon. Wea. Rev., 138, 3671-3682, https://doi.org/10.1175/2010MWR3343.1.

_ , and Coauthors, 2017: The subseasonal to seasonal (S2S) prediction project database. Bull. Amer. Meteor. Soc., 98, 163 173, https://doi.org/10.1175/BAMS-D-16-0017.1.

Waliser, D. E., 2006: Predictability of tropical intraseasonal variability. Predictability of Weather and Climate, T. Palmer and R. Hagedorn, Eds., Cambridge University Press, 275-305.

_ 2012: Predictability and forecasting. Intraseasonal Variability in the Atmosphere-Ocean Climate System, 2nd ed. W. K.-M. Lau and D. E. Waliser, Eds., Springer, 433-476.

Walsh, K. J. E., M. Fiorino, C. W. Landsea, and K. L. McInnes, 2007: Objectively determined resolution-dependent threshold criteria for the detection of tropical cyclones in climate models and reanalyses. J. Climate, 20, 2307-2314, https://doi.org/ 10.1175/JCLI4074.1.

Wang, W., M.-P. Hung, S. J. Weaver, A. Kumar, and X. Fu, 2014: MJO prediction in the NCEP Climate Forecast System version 2. Climate Dyn., 42, 2509-2520, https://doi.org/10.1007/ s00382-013-1806-9.

Wang, Z., M. T. Montgomery, and T. J. Dunkerton, 2010: Genesis of pre-Hurricane Felix (2007). Part I: The role of the easterly wave critical layer. J. Atmos. Sci., 67, 1711-1729, https:// doi.org/10.1175/2009JAS3420.1.

, W. Li, M. S. Peng, X. Jiang, R. McTaggart-Cowan, and C. A. Davis, 2018: Predictive skill and predictability of North Atlantic 
tropical cyclogenesis in different synoptic flow regimes. J. Atmos. Sci., 75, 361-378, https://doi.org/10.1175/JAS-D-17-0094.1.

Weare, B. C., and J. S. Nasstrom, 1982: Examples of extended empirical orthogonal function analyses. Mon. Wea. Rev., 110, 481-485, https://doi.org/10.1175/1520-0493(1982)110<0481: EOEEOF $>2.0 . \mathrm{CO} ; 2$.

Wheeler, M. C., and H. H. Hendon, 2004: An all-season real-time multivariate MJO index: Development of an index for monitoring and prediction. Mon. Wea. Rev., 132, 1917-1932, https://doi.org/ 10.1175/1520-0493(2004)132<1917:AARMMI>2.0.CO;2.

Xiang, B., M. Zhao, X. Jiang, S.-J. Lin, T. Li, X. Fu, and G. Vecchi, 2015a: The 3-4 week MJO prediction skill in a GFDL coupled model. J. Climate, 28, 5351-5364, https://doi.org/10.1175/ JCLI-D-15-0102.1.

— for Hurricane Sandy and Super Typhoon Haiyan in a global climate model. Mon. Wea. Rev., 143, 524-535, https://doi.org/ 10.1175/MWR-D-14-00227.1.

Zhang, C., 2005: Madden-Julian Oscillation. Rev. Geophys., 43, RG2003, https://doi.org/10.1029/2004RG000158.
Zhang, S., M. Zhao, S.-J. Lin, X. Yang, and W. Anderson, 2014: Retrieval of tropical cyclone statistics with a high-resolution coupled model and data. Geophys. Res. Lett., 41, 652-660, https://doi.org/10.1002/2013GL058879.

Zhao, H., X. Jiang, and L. Wu, 2015: Modulation of northwest Pacific tropical cyclone genesis by the intraseasonal variability. J. Meteor. Soc. Japan, 93, 81-97, https://doi.org/10.2151/ jmsj.2015-006.

$\_,-$, and _ _ 2016: Boreal summer synoptic-scale waves over the western North Pacific in multimodel simulations. J. Climate, 29, 4487-4508, https://doi.org/10.1175/JCLI-D-15-0696.1.

Zhao, M., I. M. Held, S.-J. Lin, and G. A. Vecchi, 2009: Simulations of global hurricane climatology, interannual variability, and response to global warming using a $50-\mathrm{km}$ resolution GCM. J. Climate, 22, 6653-6678, https://doi.org/10.1175/ 2009JCLI3049.1.

, and Coauthors, 2018: The GFDL global atmosphere and land model AM4.0/LM4.0: 2. Model description, sensitivity studies, and tuning strategies. J. Adv. Model. Earth Syst., 10, 735-769, https://doi.org/10.1002/2017MS001209. 
